OPEN ACCESS

Edited by:

Gregor Majdic,

University of Ljubljana, Slovenia

Reviewed by:

Helen Kamens,

Pennsylvania State University (PSU), United States

Gretchen N. Neigh,

Virginia Commonwealth University, United States

*Correspondence: Kristen E. Pleil

krp2013@med.cornell.edu

†These authors have contributed equally to this work

Specialty section:

This article was submitted to Individual and Social Behaviors, a section of the journal Frontiers in

Behavioral Neuroscience

Received: 24 April 2020 Accepted: 30 June 2020

Published: 24 July 2020

Citation:

Rivera-Irizarry JK, Skelly MJ and Pleil KE (2020) Social Isolation Stress in Adolescence, but not Adulthood,

Produces Hypersocial Behavior in Adult Male and Female C57BL/6J Mice.

Front. Behav. Neurosci. 14:129. doi: 10.3389/fnbeh.2020.00129

\section{Social Isolation Stress in Adolescence, but not Adulthood, Produces Hypersocial Behavior in Adult Male and Female C57BL/6J Mice}

\author{
Jean K. Rivera-Irizarry ${ }^{1 \dagger}$, Mary Jane Skelly ${ }^{2 \dagger}$ and Kristen E. Pleil ${ }^{1,2,3 *}$ \\ ${ }^{1}$ Graduate Program in Neuroscience, Weill Cornell Medicine Graduate School of Medical Sciences, Cornell University, \\ New York, NY, United States, 'Department of Pharmacology, Weill Cornell Medicine, Cornell University, New York, NY, \\ United States, ${ }^{3}$ Graduate Program in Pharmacology, Weill Cornell Medicine, Cornell University, New York, NY, United States
}

Chronic stress during the developmental period of adolescence increases susceptibility to many neuropsychiatric diseases in adulthood, including anxiety, affective, and alcohol/substance use disorders. Preclinical rodent models of adolescent stress have produced varying results that are species, strain, sex, and laboratory-dependent. However, adolescent social isolation is a potent stressor in humans that has been reliably modeled in male rats, increasing adult anxiety-like and alcohol drinking behaviors, among others. In this study, we examined the generalizability and sex-dependence of this model in C57BL/6J mice, the most commonly used rodent strain in neuroscience research. We also performed a parallel study using social isolation in adulthood to understand the impact of adult social isolation on basal behavioral phenotypes. We found that 6 weeks of social isolation with minimal handling in adolescence through early adulthood [postnatal day (PD) 28-70] produced a hypersocial phenotype in both male and female mice and an anxiolytic phenotype in the elevated plus-maze in female mice. However, it had no effects in other assays for avoidance behavior or on fear conditioning, alcohol drinking, reward or aversion sensitivity, or novel object exploration in either sex. In contrast, 6 weeks of social isolation in adulthood beginning at PD77 produced an anxiogenic phenotype in the light/dark box but had no effects on any other assays. Altogether, our results suggest that: (1) adolescence is a critical period for social stress in C57BL/6J mice, producing aberrant social behavior in a sex-independent manner; and (2) chronic individual housing in adulthood does not alter basal behavioral phenotypes that may confound interpretation of behavior following other laboratory manipulations.

Keywords: chronic developmental stress, anxiety, alcohol use disorder, binge alcohol drinking, reward-seeking, aversion resistance, sucrose preference, sex differences 


\section{INTRODUCTION}

Adolescence is a critical developmental period marked by increased reward-seeking and impulsivity and the establishment of apposite social behaviors (Spear, 2004; Steinberg, 2004, 2010; Romer, 2010; Leshem, 2016). In humans, adolescence is associated with increased peer affiliation and separation from family (Noom et al., 1999; Keijsers et al., 2009; Eichelsheim et al., 2010). In rodents and other mammals, it is marked by the heightened incidence of play behavior, altered social interactions, and increased exploration (Spear, 2004; Hawk et al., 2009; Trentacosta and Shaw, 2009; Walker et al., 2019). The quality and quantity of social interactions during adolescence have been linked to later-life behavioral outcomes in humans, including rates of drug and alcohol use and the formation of healthy social relationships (Bray et al., 2001; Kochenderfer-Ladd and Wardrop, 2001; Trentacosta and Shaw, 2009; Masten et al., 2012; Deutsch et al., 2015; Jager et al., 2015).

Adolescence is also marked by increased stress sensitivity, and chronic stress exposure during this period has been shown to alter brain structure and function (Paus, 2007; Eiland and Romeo, 2013). As peer interactions are especially important during adolescence (Steinberg, 2004; Jager et al., 2015), exposure to social stress may have particularly deleterious consequences on brain development and behavior (Casey et al., 2010; Platt et al., 2013; Burke et al., 2017). This increased stress sensitivity may partly explain why substance use disorders and many other psychiatric conditions frequently emerge during adolescence (Turner and Lloyd, 2004; Kessler et al., 2005, 2007; Ernst and Fudge, 2009; Casey and Jones, 2010; Blakemore and Robbins, 2012). Also, circulating gonadal hormones that emerge at puberty may influence stress responses in adolescence by modulating arousal and salience of stressful stimuli, and additionally can physiologically interact with stress hormones to alter behavior in a sex-specific manner during development and adulthood (Romeo et al., 2016; Bell, 2018). Understanding how adolescent social stress alters neurophysiology and behavior may prove crucial to treating stress-related disorders in adolescence and throughout later life.

Adolescent social isolation in rats has emerged as a preclinical model that recapitulates many of the deleterious behavioral outcomes linked to chronic adolescent stress in humans (Lukkes et al., 2009b; Butler et al., 2016; Walker et al., 2019). In male rats, this paradigm has been shown to increase anxiety-like behavior and drug and ethanol intake and decrease fear memory extinction (McCool and Chappell, 2009; Whitaker et al., 2013; Butler et al., 2014a, 2016; Karkhanis et al., 2015, 2019; Skelly et al., 2015; Yorgason et al., 2016), although these effects were not recapitulated in female rats (Butler et al., 2014b). Isolation during adolescence has also been linked to decreased social interaction in rats (Ferdman et al., 2007). Less is known about the effects of protracted adolescent isolation on these behaviors in mice, even though they are commonly used in neuroscience research, including studies that model human psychiatric conditions such as drug self-administration that require individual housing (Becker and Ron, 2014). Like humans, adolescent mice demonstrate a potentiated response to stress
(Romeo et al., 2006). Although there are some reports that chronic isolation beginning in adolescence increases depressiveand anxiety-like behaviors and drug self-administration in mice (Lopez et al., 2011; Amiri et al., 2015), these results are variable and may be strain and sex-dependent (Arakawa, 2018; Mumtaz et al., 2018; Walker et al., 2019). C57BL/6J mice are commonly used in studies of alcohol self-administration (Rhodes et al., 2005; Melendez et al., 2006; Lyons et al., 2008; Yoneyama et al., 2008; Hwa et al., 2011; Mulligan et al., 2011) and as such are regularly singly housed for long periods. However, the lasting behavioral effects of social isolation (either in adolescence or adulthood) on escalated alcohol self-administration and anxiety-like behaviors in this strain have been variable (Lopez et al., 2011; Lopez and Laber, 2015; Huang et al., 2017; Caruso et al., 2018).

Here, we evaluated the behavioral consequences of prolonged social isolation on behavior in male and female C57BL/6J mice and determined whether adolescence was a specific period of stress sensitivity. Following 6 weeks of social isolation beginning in either adolescence or adulthood, we measured anxiety, anhedonia, alcohol intake, reward and aversion sensitivity, fear memory formation, and social behavior in adulthood. We found that social isolation produced few behavioral deficits overall, however, exposure to this manipulation beginning in adolescence led to aberrant social behavior in adulthood, marked by hypersociability and reduced avoidance behavior. Overall, these results suggest that extended single housing beginning in adulthood does not robustly impact the basal behavioral state of C57BL/6J mice and that adolescence is a sensitive period for the effects of chronic social stress in this strain.

\section{METHODS}

\section{Animals}

Male and female C57BL/6J mice were purchased from Jackson Laboratories (Bar Harbor, ME, USA) at postnatal day (PD) 21 (for adolescent isolation experiment) or 63 (for adult isolation experiment) and housed on a $12 \mathrm{~h}: 12 \mathrm{~h}$ light:dark cycle with lights off at 7:30 am and ad libitum access to food and water. One week after arrival, mice were randomly assigned to socially isolated (SI, one mouse per cage) or maintained in group-housed (GH, five mice per cage) conditions for 6 weeks before behavioral testing. In the adolescent SI cohort, mice that were GH through adolescence were singly housed at PD77 for the duration of the study. In the adult SI cohort, GH mice remained in group-housed conditions. All experimental protocols were approved by the Institutional Animal Care and Use Committee at Weill Cornell Medicine following the guidelines of the NIH Guide for the Care and Use of Laboratory Animals.

\section{Behavioral Assays}

Assays were conducted under 250 lux lighting conditions as previously described (Pleil et al., 2015; Crowley et al., 2016; Marcinkiewcz et al., 2016) and Panlab SMART 3.0 video tracking software was used to track and analyze behavior unless otherwise described. All behavioral experiments commenced $2 \mathrm{~h}$ into the start of the dark cycle. Each behavioral apparatus was thoroughly cleaned with $70 \%$ ethanol before each trial. Timeline 
graphs illustrating the sequence of experiments conducted in the adolescent and adult isolation cohorts can be found in Figures 1A, 2A, respectively.

\section{Elevated Plus Maze}

The elevated plus maze (EPM) test was conducted in a plexiglass maze with two open and two closed arms $(35 \mathrm{~cm} \mathrm{l} \times 5.5 \mathrm{~cm} \mathrm{w}$, with $15 \mathrm{~cm} \mathrm{~h}$ walls for closed arms) extending from a central platform $(5.5 \mathrm{~cm} \times 5.5 \mathrm{~cm})$ elevated $50 \mathrm{~cm}$ above the floor. At the beginning of each trial, the mouse was placed in the center of the maze facing an open arm, and movement was tracked continuously for $5 \mathrm{~min}$. The total time spent on the open and closed arms of the assay and the total number of open and closed arm entries (defined as placement of all four paws into the arm) were quantified. Percent time spent in the open arms of the assay was calculated to measure anxiety-like behavior, and closed arm entries were used as a measure of locomotion.

\section{Open Field Test}

The open-field test was conducted in a plexiglass arena $(50 \times 50 \times 34.5 \mathrm{~cm})$ with a gray floor. The mouse was placed in one corner of the arena and allowed to explore freely for $30 \mathrm{~min}$. Total time spent in the center of the maze (defined as having all four paws in the $25 \mathrm{~cm} \times 25 \mathrm{~cm}$ area in the center of the arena) and periphery were quantified to calculate the percent center time. The total distance traveled in the maze $(\mathrm{cm})$ was used to measure locomotion, and percent time in the center of the maze was used to assess anxiety-like behavior.

\section{Light/Dark Box}

The light/dark box assay was conducted in a rectangular box divided into two equal compartments $(20 \mathrm{~cm} \mathrm{l} \times 40 \mathrm{~cm}$ $\mathrm{w} \times 34.5 \mathrm{~cm} \mathrm{~h}$ ), one dark with a closed lid and the other with an open top and illuminated by two $60 \mathrm{~W}$ bulbs placed $30 \mathrm{~cm}$ above the box. The two compartments were separated by a divider with a $6 \mathrm{~cm} \times 6 \mathrm{~cm}$ cut out passageway at floor level. At the beginning of each trial, the mouse was placed in a corner of the light compartment and allowed to move freely between the two compartments for $10 \mathrm{~min}$. The number of lightbox entries and total time spent in the light compartment as compared to the dark compartment was used to assess anxiety-like behavior.

\section{Social Interaction Test}

The social interaction test was conducted in three 10-min phases in an open plexiglass arena $(50 \mathrm{~cm} \times 50 \mathrm{~cm} \times 34.5 \mathrm{~cm})$, and mice could explore freely during each phase. Between each testing phase, the experimental mouse was briefly placed in a holding cage while the experimenter altered the arena settings as follows: phase 1: empty arena; phase 2: two empty wire mesh cups (diameter $4^{\prime \prime}$, height $4^{\prime \prime}$ ) located at opposite corners of the arena $10 \mathrm{~cm}$ from each wall; phase 3: a novel age- and sex-matched mouse of the same strain was placed inside one of the two cups, while the other cup remained empty. The placement of the cups and social partner were pseudorandom and counterbalanced. Interaction zones for each cup were defined as encompassing a $5 \mathrm{~cm}$ radius around the center of the cup, and the ratio of interaction time with the social partner vs. the empty cup during phase 3 was used to determine a social preference score.

\section{Novel Object Interaction}

The novel object interaction assay was conducted under the same conditions and using the same analyses as the social interaction test (see above) but using objects, to assess whether effects observed in novel social partner preference could be generalized to a non-social novel object. The objects used in this experiment included plastic cuboids with orange color $(3 \mathrm{~cm} \times 3 \mathrm{~cm} \times 6 \mathrm{~cm})$ and half-sphered plastic cylinders with the blue color of the same dimensions, as described in previous publications (Lueptow, 2017; Tian et al., 2019); these objects were determined to be of equal interest to C57BL/6J mice in pilot testing. The objects were affixed to the floor of the arena during behavioral testing, which proceeded as follows: phase 1: empty arena; phase 2: two versions of the same object located at opposite corners of the arena $10 \mathrm{~cm}$ from each wall; phase 3: a novel object replaced one of the two familiar objects in the arena. The ratio of interaction time with the novel vs. familiar object during phase 3 was used as a novel object preference score.

\section{Fear Conditioning}

Fear conditioning was performed in an operant box with a stainless-steel grid floor within a sound-attenuating chamber (Colbourn Instruments, Allentown, PA, USA). The mouse was placed in the chamber at the beginning of the test, and following a $5 \mathrm{~min}$ habituation period received six pairings of a $30 \mathrm{~s}$, $80 \mathrm{~dB}$ tone (conditioned stimulus, $\mathrm{CS}$ ) co-terminating with a $2 \mathrm{~s}, 0.5 \mathrm{~mA}$ foot shock (unconditioned stimulus, US) separated by pseudorandom intra-interval times (from 31-119 s, with an average ITI of $75.5 \mathrm{~s}$ ). Video tracking and FreezeFrame software (Colbourn Instruments, Allentown, PA, USA) were used to assess freezing behavior during the $28 \mathrm{~s}$ period preceding the shock across tone/shock presentations.

\section{Home Cage Ethanol Drinking}

We used a modified version of the standard Drinking in the Dark (DID) binge ethanol drinking paradigm (mDID) to assess binge ethanol intake under limited-access conditions as well as 24 -h preference for ethanol over water. Mice were singly housed for several days before the first ethanol presentation. For each mDID cycle, the home cage water bottle was replaced with a bottle containing $20 \%$ (cycles $1-4$ ) or $30 \%$ (cycles 5-6) ethanol for $2 \mathrm{~h}$ beginning $3 \mathrm{~h}$ into the dark cycle for three days. On day 4, two bottles (one containing ethanol solution, one containing water) were placed in the cage for $24 \mathrm{~h}$ (bottles were weighted after $2 \mathrm{~h}, 4 \mathrm{~h}$, and $24 \mathrm{~h}$ of access). Bottle weights were used to calculate ethanol and water consumption daily (normalized to body weight) and $24 \mathrm{~h}$ ethanol preference on day 4, calculated as the ratio of the volume of liquid consumed from the ethanol bottle to the water bottle.

\section{Aversion-Resistant Ethanol Drinking}

Consumption and preference of quinine-adulterated ethanol over water in a two-bottle choice home cage assay was measured to evaluate aversion-resistant ethanol drinking behavior. Mice received $4 \mathrm{~h}$ of access to two bottles, one containing $20 \%$ ethanol adulterated with $100 \mu \mathrm{M}$ (Days 1 and 2) or $250 \mu \mathrm{M}$ (Day 3) 

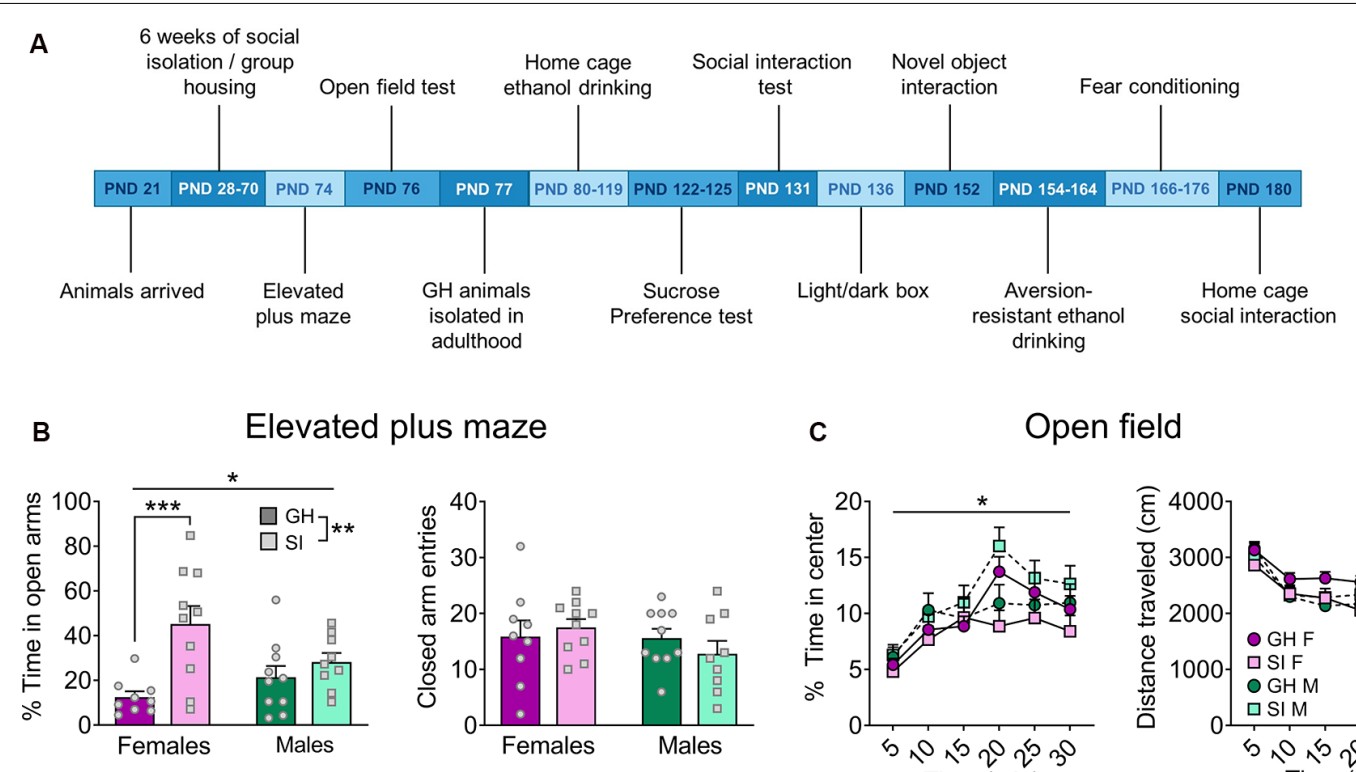

D

Social interaction
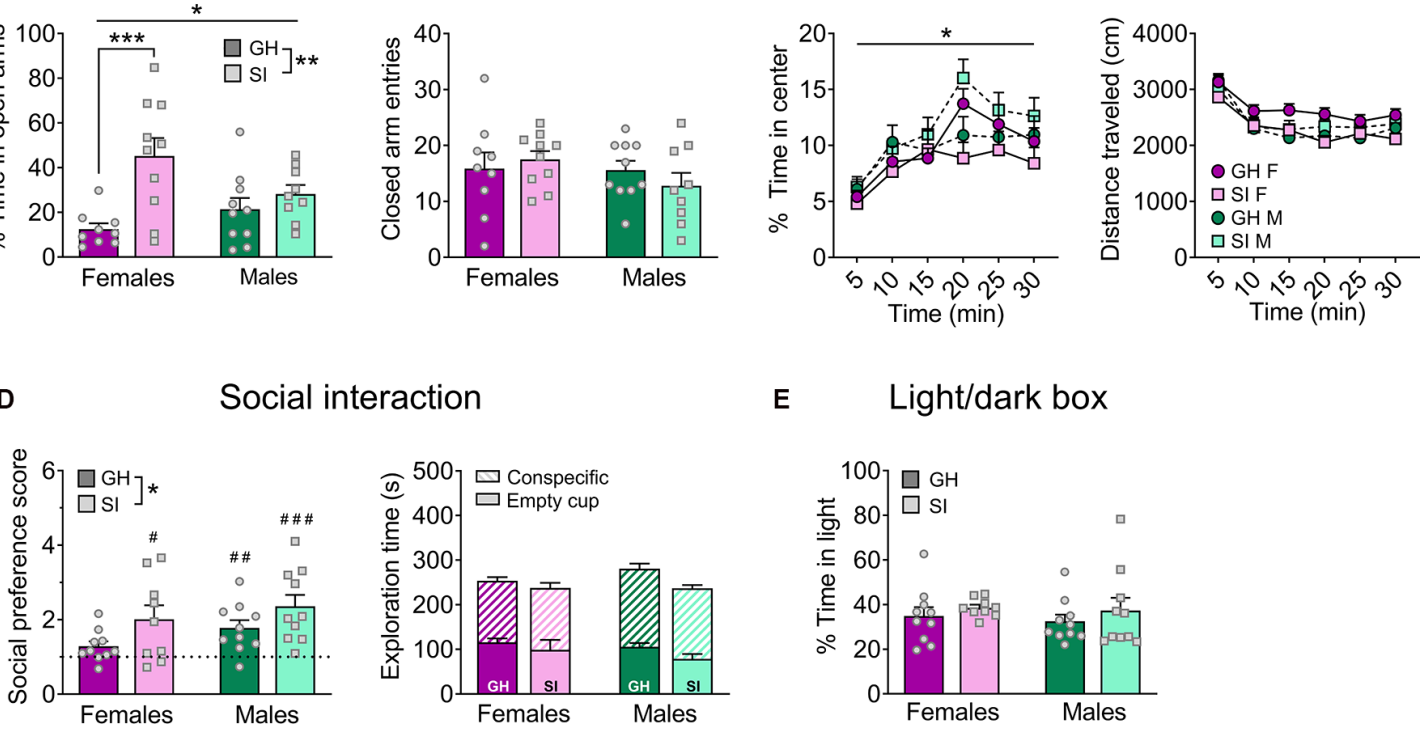

E Light/dark box
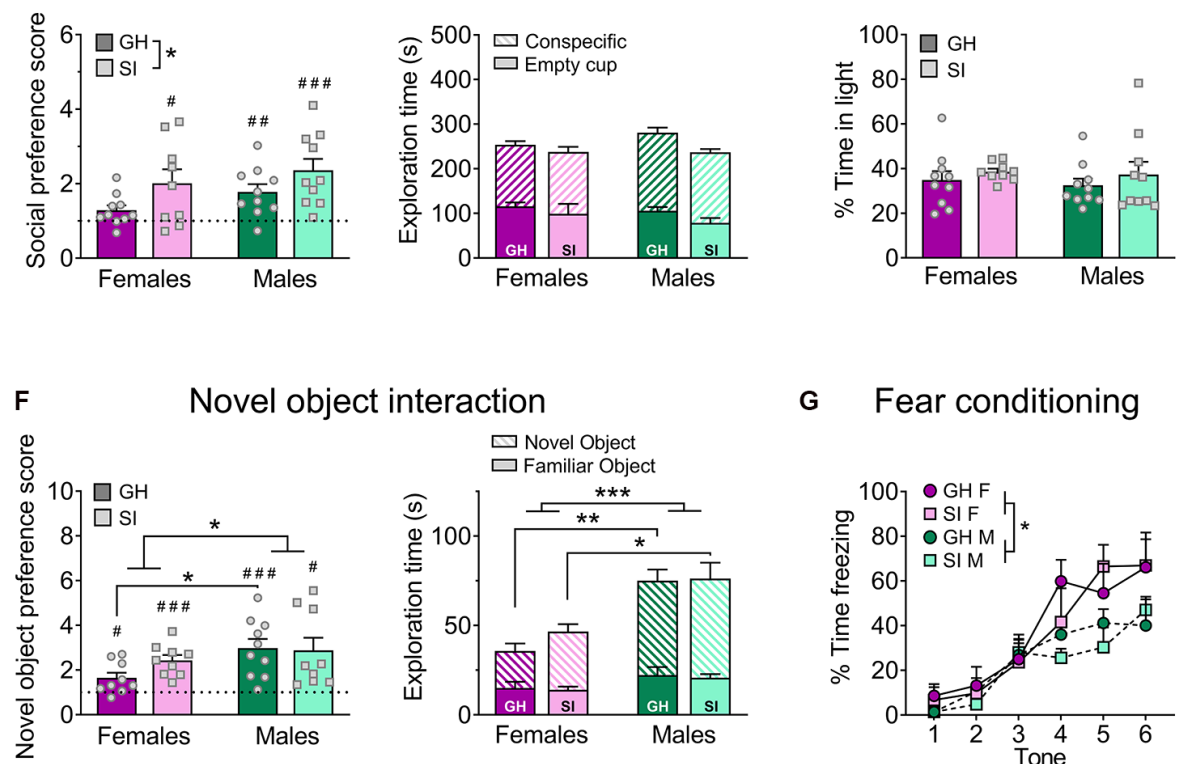

\section{G $\quad$ Fear conditioning}

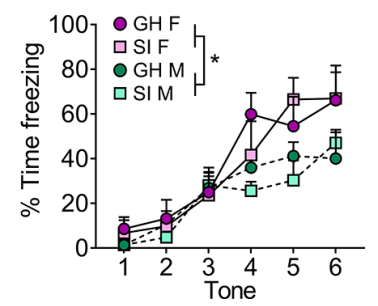

FIGURE 1 | Adolescent social isolation behavior battery. (A) Experimental timeline. (B) In the elevated plus-maze (EPM), adolescent social isolation (SI) increases the percent time spent exploring the open arms, an effect driven by females (left), without altering locomotor activity as measured by closed arm entries (right). (C) Adolescent SI oppositely affects the percent time spent exploring the center of an open field in males and females (left) but does not affect the distance traveled in this assay (right). (D) On the social interaction test, all but group-housed (GH) females display a significant preference for a novel social partner over an empty cup, and adolescent SI increases preference (left) without impacting total time spent exploring both objects (right). (E) Adolescent SI does not affect anxiety-like behavior in the light/dark box. (F) All groups display a preference for a novel object over a familiar one, and this preference was greater in males than females but unaffected by adolescent SI (left). The total time spent exploring both objects is likewise increased in males compared to females (right). (G) Females display enhanced fear conditioning compared to males, but adolescent SI does not alter this measure. Data are expressed as means + SEM; ${ }^{*} p<0.05,{ }^{* *} p<0.01,{ }^{* * *} p<0.001$ between groups; $" p<0.05,{ }^{\# \#} p<0.01,{ }^{\# \#} p<0.001$ compared to null hypothesis of preference score $=1$.

quinine hemisulfate (Sigma-Aldrich, St. Louis, MO, USA) and the other containing water. Bottle placement was pseudorandom and switched daily, and consumption and preference were measured as described for mDID.

\section{Sucrose Preference Test}

A similar procedure to that described above was used to evaluate consumption and preference for $1 \%(\mathrm{w} / \mathrm{v})$ sucrose solution vs. water, except that mice were given access to 

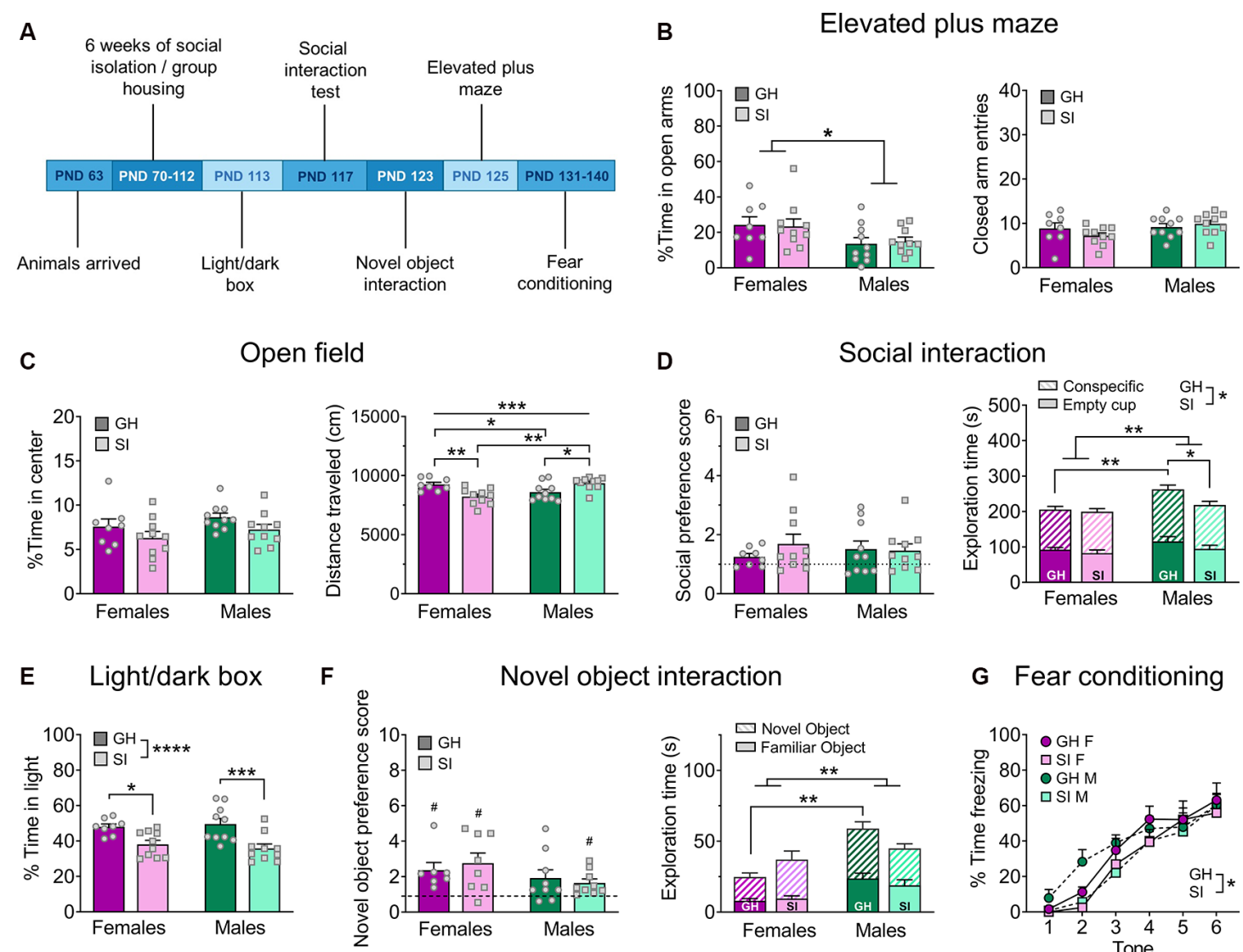

\section{G Fear conditioning}

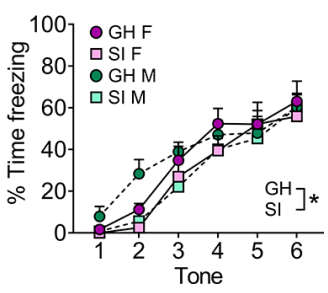

FIGURE 2 | Adult isolation behavior battery. (A) Experimental timeline. (B) Females spend more time exploring the open arms of the EPM, but adult SI does not influence this measure (left); there is no difference in general locomotor behavior, measured by the number of entries into the closed arms (right). (C) There are no effects of sex or adult SI on the percent time spent exploring the center of the open field (OF; left), however, there is a sex-dependent effect of adult SI on the total distance traveled in the OF (right). (D) Adult SI does not alter preference for a novel social partner over an empty cup in the social interaction test (left) but does decrease total time spent interacting with the social partner and empty cup, an effect driven by males (right). GH males also spend more total time exploring both objects compared to GH females. (E) Adult SI decreases the percent time spent exploring the light side of the light/dark box in both males and females. (F) In the novel object interaction test, all groups except GH males display a preference for a novel vs. familiar object (left), however, this is driven by greater overall interaction time with both objects in males (right). (G) Adult SI mice show delayed fear acquisition compared to GH mice. Data are expressed as means + SEM; ${ }^{*} p<0.05$, ${ }^{\star \star} p<0.01,{ }^{\star \star \star} p<0.001,{ }^{\star \star \star \star} p<0.001$ between groups; ${ }^{\#} p<0.05$ compared to null hypothesis of preference score $=1$.

the sucrose and water bottles for $24 \mathrm{~h}$ per day. Intake and preference were measured every $24 \mathrm{~h}$ for four consecutive days. For all drinking experiments, empty "dummy" cages on the same rack as housed behavior mice received the same ethanol, sucrose or water bottle replacement, and consumption was adjusted for a leak from dummy bottles and normalized to body weight.

\section{Home Cage Social Interaction}

Home cage social interaction with a novel same-sex conspecific mouse was conducted in the experimental mouse's home cage $(28 \mathrm{~cm} \times 18 \mathrm{~cm} \times 12.5 \mathrm{~cm})$. The novel mouse was placed into the cage and overhead video was used to record behavior for $5 \mathrm{~min}$. An experimenter blind to condition hand-scored discrete behaviors performed by the experimental mouse, including the number and duration of the total, head-to-head, and head-to-tail social interactions, as well as digging and climbing bouts.

\section{Statistical Analysis}

Statistical analyses were conducted using GraphPad Prism 8 software. Distributions of data within the group were analyzed for normality, and outliers were identified using Q-Q plots and confirmed by the Rout method $(Q=0.5 \%)$; when an individual mouse's behavior was identified as an outlier for at least half of the reported dependent measures for a given behavioral assay, it was excluded from analysis for that assay only and reported in the "Results" section. No animal was excluded from analysis on more than one behavioral assay. Two-way analysis of variance (ANOVA) was used to assess the effects of housing condition and sex on behavior in the elevated plus-maze, open field test (adult cohort), novel object test, light/dark box, and social interaction assays. Two-way repeated-measures ANOVAs (RM ANOVA) or two-factor mixed models were used to assess the effects of housing conditions on home-cage drinking behaviors within sex over time. Three-way RM ANOVA was used to assess the freezing across consecutive tone/shock pairings in the fear 
conditioning assay and behavior in the open field test across time (adolescent cohort). Equal variance across time was not assumed in RM ANOVAs with three or more repeated measures, and a Greenhouse-Geisser correction of degrees of freedom was used. Significant effects in all ANOVAs were followed up with post hoc two-tailed $t$-tests corrected for multiple comparisons using the Holm-Sidak method, and adjusted $p$-values are presented. Alpha values of 0.05 were used throughout all analyses, and data are presented as mean + SEM.

\section{RESULTS}

\section{Elevated Plus Maze}

Following 6 weeks of adolescent SI or GH conditions, mice underwent testing in the EPM to assess differences in anxiety-like behavior (Figure 1B; GH females $n=9$, GH males $n=10$, SI females $n=10$, SI males $n=9$; one $\mathrm{GH}$ female met outlier exclusion criteria and was excluded from this assay). A two-way ANOVA comparing the percent time spent on the open arms revealed a main effect of housing condition $\left(F_{(1,34)}=12.78\right.$, $p=0.001)$ but no main effect of $\operatorname{sex}\left(F_{(1,34)}=0.53, p=0.472\right)$ and a significant interaction between sex and housing condition $\left(F_{(1,34)}=0.41, p=0.026\right)$. Post hoc analysis showed that this effect was driven by females, as SI females spent significantly more time on the open arms than their GH counterparts $\left(t_{(34)}=4.17\right.$, adjusted $\left.p=0.0004\right)$, while SI males did not (adjusted $p>0.05)$. A two-way ANOVA on the number of closed arm entries revealed no effects of housing $\left(F_{(1,34)}=0.08\right.$, $p=0.776)$ or sex $\left(F_{(1,34)}=1.41, p=0.776\right)$, nor a sex by housing condition interaction $\left(F_{(1,34)}=1.10, p=0.301\right)$, suggesting that the increased open arm exploration in SI females was not due to a general increase in locomotion.

In contrast, social isolation during adulthood did not alter anxiety-like behavior on the EPM (Figure 2B). A two-way ANOVA revealed a main effect of $\operatorname{sex}\left(F_{(1,34)}=6.66, p=0.014\right)$ but no main effect of housing condition $\left(F_{(1,34)}=0.01, p=0.928\right)$ nor a sex by housing condition interaction $\left(F_{(1,34)}=0.10\right.$, $p=0.753)$. Despite this significant main effect of sex in the omnibus test, post hoc analysis did not reveal any significant differences between males and females (adjusted $p>0.05$ ). A two-way ANOVA on the number of closed arm entries revealed no effects of $\operatorname{sex}\left(F_{(1,34)}=3.17, p=0.084\right)$ or housing condition $\left(F_{(1,34)}=0.33, p=0.569\right)$, nor was there a significant interaction between these factors $\left(F_{(1,34)}=1.95, p=0.171\right)$.

\section{Open Field Test}

To further investigate the impact of adolescent social isolation on anxiety-like and locomotor behavior in early adulthood, we next compared open field exploration in GH and SI female and male mice (Figure 1C; $n=10$ per group). A three-way RM ANOVA comparing the impact of sex and adolescent housing condition on the percent time spent in the center of an open field across time $(30 \mathrm{~min}$ total, broken into 5 min intervals) revealed a significant main effect of time $\left(F_{(5,180)}=18.63, p<0.0001\right)$ but no effects of $\operatorname{sex}\left(F_{(1,36)}=3.20\right.$, $p=0.082)$ or housing condition $\left(F_{(1,36)}=0.001, p=0.971\right)$. No significant interactions were identified between time and sex $\left(F_{(5,180)}=0.31, p=0.906\right)$, time and housing condition $\left(F_{(5,180)}=0.31, p=0.904\right)$, or sex and housing condition $\left(F_{(1,36)}=3.35, p=0.075\right)$. While there was a significant three-way time by sex by housing condition interaction $\left(F_{(5,180)}=2.94\right.$, $p=0.014)$, post hoc analysis did not reveal any significant comparisons (adjusted $p s>0.05$ ). A three-way RM ANOVA comparing the total distance traveled in the open field across these time points revealed a significant main effect of time $\left(F_{(5,180)}=57.65, p<0.0001\right)$ but no main effects of sex $\left(F_{(1,36)}=0.53, p=0.473\right)$ or housing condition $\left(F_{(1,36)}=1.66\right.$, $p=0.205)$. There was an interaction between time and sex $\left(F_{(5,180)}=2.41, p=0.038\right)$ but no significant interaction between time and housing condition $\left(F_{(5,180)}=0.85, p=0.516\right)$ or sex and housing condition $\left(F_{(1,36)}=4.01, p=0.052\right)$, and no three-way interaction between time, sex, and housing condition $\left(F_{(5,180)}=1.57, p=0.171\right)$. Post hoc analysis did not reveal any significant differences between sexes at any time point, however (adjusted $p>0.05$ ).

In the adult SI cohort, we used a 10 min open field test (Figure 2C; GH females $n=8$, GH males $n=10$, SI females $n=10$, SI males $n=10$ ). A two-way ANOVA comparing the percent time in the center of this assay did not reveal a main effect of sex $\left(F_{(1,34)}=2.29, p=0.139\right)$ or housing condition $\left(F_{(1,34)}=4.07\right.$, $p=0.051)$, and the interaction between these variables also failed to achieve significance $\left(F_{(1,34)}=0.01, p=0.931\right)$. Interestingly, a two-way ANOVA comparing the total distance traveled during this 5 min assay did not reveal main effects of $\operatorname{sex}\left(F_{(1,34)}=1.38\right.$, $p=0.248)$ or housing condition $\left(F_{(1,34)}=0.41, p=0.526\right)$ but did reveal a significant interaction between these factors $\left(F_{(1,34)}=18.72, p=0.001\right)$. Post hoc comparisons revealed that $\mathrm{GH}$ females traveled a greater distance than their SI counterparts $\left(t_{(34)}=3.41\right.$, adjusted $\left.p=0.005\right)$ while $\mathrm{GH}$ males traveled significantly less distance in this assay than SI males $\left(t_{(34)}=2.69\right.$, adjusted $p=0.021)$. Furthermore, the total distance traveled was higher in $\mathrm{GH}$ females than $\mathrm{GH}$ males $\left(t_{(34)}=2.17\right.$, adjusted $p=0.037)$, and higher in SI males than SI females $\left(t_{(34)}=4.01\right.$, adjusted $p=0.001$ ).

\section{Social Interaction Test}

To determine whether chronic social isolation during adolescence effects adult social behavior, mice in the adolescent SI cohort underwent a social interaction test (Figure 1D; $\mathrm{GH}$ females $n=10$, GH males $n=10$, SI females $n=9$, SI males $n=10$ ). Male and female mice reared in isolation, as well as GH males, demonstrated a significant preference for a social partner as compared to an empty cup (onesample $t$-tests; $\mathrm{GH}$ males, $t_{(9)}=2.15, p=0.004$; SI females, $t_{(8)}=2.69, p=0.027$; SI males, $\left.t_{(9)}=4.40, p=0.001\right)$; however adolescent $\mathrm{GH}$ females did not demonstrate this social preference $\left(t_{(9)}=2.15, p=0.060\right)$. Interestingly, a two-way ANOVA analyzing preference for a social partner over a non-social object revealed a significant main effect of housing condition $\left(F_{(1,35)}=5.98, p=0.019\right)$ but no main effect of $\operatorname{sex}\left(F_{(1,35)}=2.49, p=0.123\right)$ or interaction between these factors $\left(F_{(1,35)}=0.07, p=0.787\right)$. However, post hoc analysis did not reveal any significant differences in social preference between GH and SI animals of either sex (adjusted $p>0.05$ ). 
A two-way ANOVA assessing general activity in this assay, as measured by combining the total time spent exploring both a social partner and a non-social empty cup, revealed no significant differences between groups (main effect of sex: $F_{(1,35)}=0.50, p=0.484$; main effect of housing condition: $F_{(1,35)}=2.69, p=0.110$; sex by housing condition interaction: $\left.F_{(1,35)}=0.55, p=0.462\right)$.

In the adult SI cohort (Figure 2D; GH females $n=8, \mathrm{GH}$ males $n=10$, SI females $n=10$, SI males $n=10$ ), no group demonstrated a reliable preference for a social partner over an empty cup (one-sample $t$-tests; GH females: $t_{(7)}=2.23, p=0.060$; GH males: $t_{(9)}=1.87, p=0.094$; SI females: $t_{(9)}=2.10, p=0.065$; SI males: $\left.t_{(9)}=2.05, p=0.070\right)$. A two-way ANOVA did not reveal significant differences in social preference between groups (main effect of sex: $F_{(1,29)}=3.15, p=0.086$; main effect of housing condition: $F_{(1,29)}=0.02, p=0.896$; sex by housing condition interaction: $\left.F_{(1,29)}=0.59, p=0.448\right)$. A two-way ANOVA comparing the total combined time spent exploring both the non-social object (empty cup) and social partner revealed significant main effects of sex $\left(F_{(1,34)}=10.04\right.$, $p=0.003)$ and housing condition $\left(F_{(1,34)}=4.32, p=0.045\right)$, but there was no interaction between these factors $\left(F_{(1,34)}=2.51\right.$, $p=0.122$ ). Follow-up post hoc analyses revealed that GH males spent more combined time exploring a social partner and empty cup than GH females $\left(t_{(34)}=3.27\right.$, adjusted $\left.p=0.010\right)$ and SI males $\left(t_{(34)}=2.67\right.$, adjusted $\left.p=0.034\right)$.

\section{Light/Dark Box}

A two-way ANOVA did not reveal any effects of adolescent social isolation or sex (Figure 1E; $n=10$ per group) on the percent time spent in the light side of a light/dark box (main effect of sex: $F_{(1,35)}=0.21, p=0.646$; main effect of housing condition: $F_{(1,35)}=1.21, p=0.279$; sex by housing condition interaction: $F_{(1,35)}=0.023, p=0.879$ ). A two-way ANOVA comparing the effects of 6 weeks of adult social isolation vs. group housing conditions on behavior in the light/dark box in males and females (Figure 2E; GH females $n=8$, GH males $n=10$, SI females $n=10$, SI males $n=10$ ) revealed a significant main effect of housing condition $\left(F_{(1,34)}=21.78, p<0.0001\right)$, but no main effect of sex $\left(F_{(1,34)}=0.020, p=0.886\right)$ or significant interaction between these variables $\left(F_{(1,34)}=0.550, p=0.463\right)$. Post hoc analysis revealed that $\mathrm{GH}$ animals spent significantly more time in the light compartment of the light/dark box than their SI counterparts (GH males vs. SI males: $t_{(34)}=3.94$, adjusted $p=0.0008$; $\mathrm{GH}$ females vs. SI females: $t_{(34)}=2.70$, adjusted $p=0.011)$.

\section{Novel Object Interaction}

To determine whether the increased social exploration observed following adolescent social isolation could be generalized to non-social contexts, we performed a novel object interaction task designed similarly to the social interaction task described above (Figure 1F). GH females $(n=9)$ demonstrated a preference for a novel object over a familiar object (one-sample $t$-test, $\left.t_{(8)}=2.71, p=0.026\right)$, as did GH males $\left(n=10 ; t_{(9)}=4.83\right.$, $p=0.0009)$, SI females $\left(n=9 ; t_{(8)}=6.02, p=0.0003\right)$, and SI males $\left(n=9 ; t_{(8)}=3.29, p=0.011\right)$. A two-way ANOVA comparing novel object preference across groups revealed a significant main effect of $\operatorname{sex}\left(F_{(1,33)}=5.20, p=0.029\right)$ but no main effect of housing condition $\left(F_{(1,33)}=0.766, p=0.387\right)$ or significant interaction between these factors $\left(F_{(1,33)}=1.31, p=0.261\right)$. Post hoc analysis revealed that GH males exhibited a significantly increased novel object preference as compared to $\mathrm{GH}$ females $\left(t_{(33)}=2.45\right.$, adjusted $\left.p=0.039\right)$. To assess general exploratory behavior in this assay, we compared the total time that animals in each group spent exploring both the novel plus familiar objects in this assay. A two-way ANOVA revealed a significant main effect of sex $\left(F_{(1,33)}=17.91, p=0.0002\right)$, but no main effect of housing condition $\left(F_{(1,33)}=0.54, p=0.469\right)$ or interaction between these factors $\left(F_{(1,33)}=0.36, p=0.553\right)$. Post hoc analysis revealed that $\mathrm{GH}$ females spent significantly less time exploring the novel and familiar objects than GH males $\left(t_{(33)}=3.46\right.$, adjusted $p=0.002)$. Consistent with this, SI females also spent less time exploring these objects that SI males $\left(t_{(33)}=2.54\right.$, adjusted $p=0.016)$. Altogether, these results suggest that while there are sex differences in the preference for and exploration of novel objects over familiar, adolescent social isolation had no effect on this task. In contrast, adolescent social isolation increased preference for a social partner, suggesting that its effects were specific to a social context.

In the adult SI cohort (Figure 2F), GH females displayed a significant preference for the novel object $\left(n=7 ; t_{(6)}=3.13\right.$, $p=0.026)$, as did SI females $\left(n=8 ; t_{(7)}=3.07, p=0.017\right)$ and SI males $\left(n=9 ; t_{(8)}=2.84, p=0.022\right)$, but not GH males $\left(n=9 ; t_{(8)}=1.99, p=0.082\right)$; one GH and one SI female met outlier criteria and were excluded from statistical analysis for this assay. A two-way ANOVA comparing novel object preference across groups revealed no significant differences between groups (main effect of sex: $F_{(1,29)}=3.15, p=0.896$; main effect of housing condition: $F_{(1,29)}=0.017, p=0.896$; sex by housing condition interaction: $\left.F_{(1,29)}=0.59, p=0.448\right)$. A two-way ANOVA comparing the total combined time spent exploring the novel and familiar objects revealed a significant main effect of $\operatorname{sex}\left(F_{(1,29)}=10.64, p=0.002\right)$, but no main effect of housing condition $\left(F_{(1,29)}=0.019, p=0.890\right)$ or sex by housing interaction $\left(F_{(1,29)}=4.13, p=0.051\right)$. Post hoc tests revealed that $\mathrm{GH}$ males spent significantly more combined time exploring a social partner and novel object than GH females $\left(t_{(29)}=3.68\right.$, adjusted $p=0.002$ ).

\section{Fear Conditioning}

We next assessed whether adolescent social isolation impacts fear learning by measuring acquisition of freezing behavior in response to a foot shock-paired tone (assessed by freezing during tone presentation across six consecutive tone/shock pairings; Figure 1G). A three-way RM ANOVA was used to measure the effects of sex and adolescent housing condition on freezing behavior across time ( $\mathrm{GH}$ females $n=5$, SI females $n=4, \mathrm{GH}$ males $n=5$, SI males $n=5)$. This test revealed a significant main effect of time, as expected $\left(F_{(3,045,45)}=34.28, p<0.0001\right)$. A main effect of sex also emerged $\left(F_{(1,15)}=5.36, p=0.035\right)$ as well as a significant time by sex interaction $\left(F_{(5,75)}=2.68, p=0.027\right)$. There was no significant main effect of housing condition $\left(F_{(1,15)}=0.23, p=0.638\right)$, time by housing condition interaction 
$\left(F_{(5,75)}=0.80, p=0.550\right)$, sex by housing condition interaction $\left(F_{(1,15)}=0.010, p=0.919\right)$, or time by sex by housing condition interaction $\left(F_{(5,75)}=0.63, p=0.680\right)$. Post hoc comparisons did not reveal any significant sex-dependent differences at any time point, however (adjusted $p>0.05$ ).

We also assessed fear conditioning in the adult SI cohort (Figure 2G; GH female $n=8$, GH male $n=10$, SI female $n=10$, SI male $n=10)$. A three-way RM ANOVA revealed a main effect of time $\left(F_{(3.851,130.9)}=78.78, p<0.0001\right)$, as well as a main effect of housing condition $\left(F_{(1,34)}=4.17, p=0.048\right)$ but no main effect of sex $\left(F_{(1,34)}=0.069, p=0.793\right)$. There was no interaction between time and $\operatorname{sex}\left(F_{(5,170)}=1.15, p=0.336\right)$, time and housing condition $\left(F_{(5,170)}=1.26, p=0.285\right)$, or sex and housing condition $\left(F_{(1,34)}=0.153, p=0.697\right)$, nor was there a significant three-way interaction between these variables $\left(F_{(5,170)}=0.669, p=0.646\right)$. Post hoc analysis did not reveal any significant differences in freezing behavior across groups at any time point (adjusted $p>0.05$ ).

\section{Home Cage Ethanol Drinking}

As previous studies in rodents have demonstrated that adolescent social isolation increases home cage ethanol self-administration (McCool and Chappell, 2009; Butler et al., 2014a, 2016; Skelly et al., 2015), we next assessed whether adolescent social isolation affects binge ethanol drinking in male and female C57BL/6J mice across time using a modified version of the standard DID paradigm that allowed us to assess ethanol preference on day 4 of each DID cycle (Figures 3A,D; $n=10$ per group). A mixed-effects analysis was used to evaluate consumption of $20 \%$ ethanol across four cycles in $\mathrm{GH}$ and SI females (Figure 3A, left), revealing a main effect of cycle $\left(F_{(6.372,112.6)}=4.32, p<0.0001\right)$ but no main effect of housing condition $\left(F_{(1,18)}=1.24, p=0.280\right)$ or interaction between these variables $\left(F_{(15,265)}=1.43, p=0.132\right)$. To ensure that a group difference was not being obscured by a ceiling effect, we next increased the concentration of ethanol to $30 \%$ for two cycles, and a mixed-effects analysis revealed no effects or interactions at this concentration either (main effect of cycle: $F_{(3.621,60.52)}=1.77, p=0.153$; main effect of housing condition: $F_{(1,17)}=0.219, p=0.645$; time by housing condition interaction: $\left.F_{(7,117)}=1.72, p=0.111\right)$. We also found no effect of social isolation on ethanol preference at either concentration in females (Figure 3A, right). A mixed-effects analysis of $20 \%$ ethanol preference revealed no effects (main effect of cycle: $F_{(3,49)}=0.097, p=0.961$; main effect of housing condition: $F_{(1,18)}=1.71, p=0.207$; cycle by housing condition interaction: $\left.F_{(3,49)}=2.19, p=0.101\right)$. Similarly, a two-way RM ANOVA assessing 30\% ethanol preference revealed no effects (main effect of time: $F_{(1,17)}=1.07, p=0.316$; main effect of housing condition: $F_{(1,17)}=3.83, p=0.252$; time by housing condition interaction: $\left.F_{(1,17)}=1.83, p=0.194\right)$.

Similar to females, social isolation did not affect ethanol consumption or preference in males (Figure 3D, left). A mixed-effects analysis of $20 \%$ ethanol consumption (Figure 3D; $n=10$ per group) revealed a significant main effect of cycle $\left(F_{(7.450,132.6)}=4.10, p<0.001\right)$, but no main effect of housing condition $\left(F_{(1,18)}=0.004, p=0.947\right)$ or interaction between these factors $\left(F_{(15,267)}=0.527, p=0.924\right)$. A mixed-effects analysis of $30 \%$ ethanol intake also revealed a main effect of cycle $\left(F_{(7,121)}=7.36, p<0.001\right)$, but no main effect of housing condition $\left(F_{(1,18)}=1.29, p=0.270\right)$ or significant cycle by housing condition interaction $\left(F_{(7,121)}=1.63, p=0.132\right)$. A mixed-effects analysis of $20 \%$ ethanol preference (Figure 3D, right) compared to water revealed no effects (main effect of cycle: $F_{(2.357,38.49)}=0.325, p=0.758$; main effect of housing condition: $F_{(1,18)}=0.213, p=0.649$; cycle by housing condition interaction: $\left(F_{(3,49)}=2.06, p=0.117\right)$. Similarly, a mixed effects analysis assessing 30\% ethanol preference did not reveal significant group differences (main effect of cycle: $F_{(1,35)}=1.88, p=0.179$; main effect of housing condition: $F_{(1,35)}=0.151, p=0.699$; cycle by housing condition interaction: $\left.F_{(1,35)}=0.536, p=0.468\right)$.

\section{Aversion-Resistant Ethanol Drinking}

To assess whether adolescent social isolation alter aversionresistant ethanol consumption, we measured home cage DID intake using $20 \%$ ethanol adulterated with quinine (Figures 3B,E). Mice were given $4 \mathrm{~h}$ access to $20 \%$ ethanol containing either $100 \mu \mathrm{M}$ quinine (days 1 and 2, average used for analysis) or $250 \mu \mathrm{M}$ quinine (day 3). Among female mice (ns = 9), a two-way RM ANOVA for quinine-adulterated ethanol intake did not reveal any significant differences (Figure 3B; main effect of quinine concentration: $F_{(1,16)}=4.21$, $p=0.056$; main effect of housing condition: $F_{(1,16)}=0.175$, $p=0.681$; concentration by housing condition interaction: $\left.F_{(1,16)}=0.001, p=0.977\right)$. Similarly, a two-way RM ANOVA assessing quinine-adulterated ethanol preference revealed no main effects of housing condition $\left(F_{(1,16)}=3.62, p=0.074\right)$ or quinine concentration $\left(F_{(1,16)}=1.67, p=0.214\right)$, nor any significant interaction between these variables $\left(F_{(1,16)}=0.049\right.$, $p=0.826)$. In male mice ( $\mathrm{GH} n=10$, SI $n=9)$, there was a significant main effect of quinine concentration on ethanol intake (Figure 3E; $F_{(1,17)}=2.93, p=0.105$ ), with the higher dose of quinine suppressing ethanol consumption. However, there was no significant main effect of housing condition $\left(F_{(1,17)}=2.93, p=0.105\right)$, nor a significant interaction between these factors $\left(F_{(1,17)}=0.128, p=0.724\right)$. A two-way RM ANOVA comparing ethanol preference across quinine concentrations did not reveal any significant differences between GH and SI male mice (main effect of quinine concentration: $F_{(1,17)}=1.29$, $p=0.271$; main effect of housing condition: $F_{(1,17)}=0.108$, $p=0.746$; concentration by housing condition interaction: $\left.F_{(1,17)}=0.001, p=0.981\right)$.

\section{Sucrose Preference Test}

To determine whether social isolation during adolescence impacts general reward sensitivity, we measured $1 \%(\mathrm{w} / \mathrm{v})$ sucrose preference vs. water across three days (Figures 3C,F). A two-way RM ANOVA comparing adolescent GH $(n=10)$ and SI $(n=9)$ female mice revealed a significant main effect of time (Figure 3C; $F_{(1.687,28.68)}=4.32, p=0.028$ ) but no main effect of housing condition $\left(F_{(1,17)}=0.342, p=0.566\right)$ or interaction between these variables $\left(F_{(2,34)}=0.255, p=0.775\right)$. In male mice, no differences in sucrose preference emerged (Figure 3F; main effect of time: $F_{(1.418,25.53)}=2.57, p=0.110$; 
A

Females
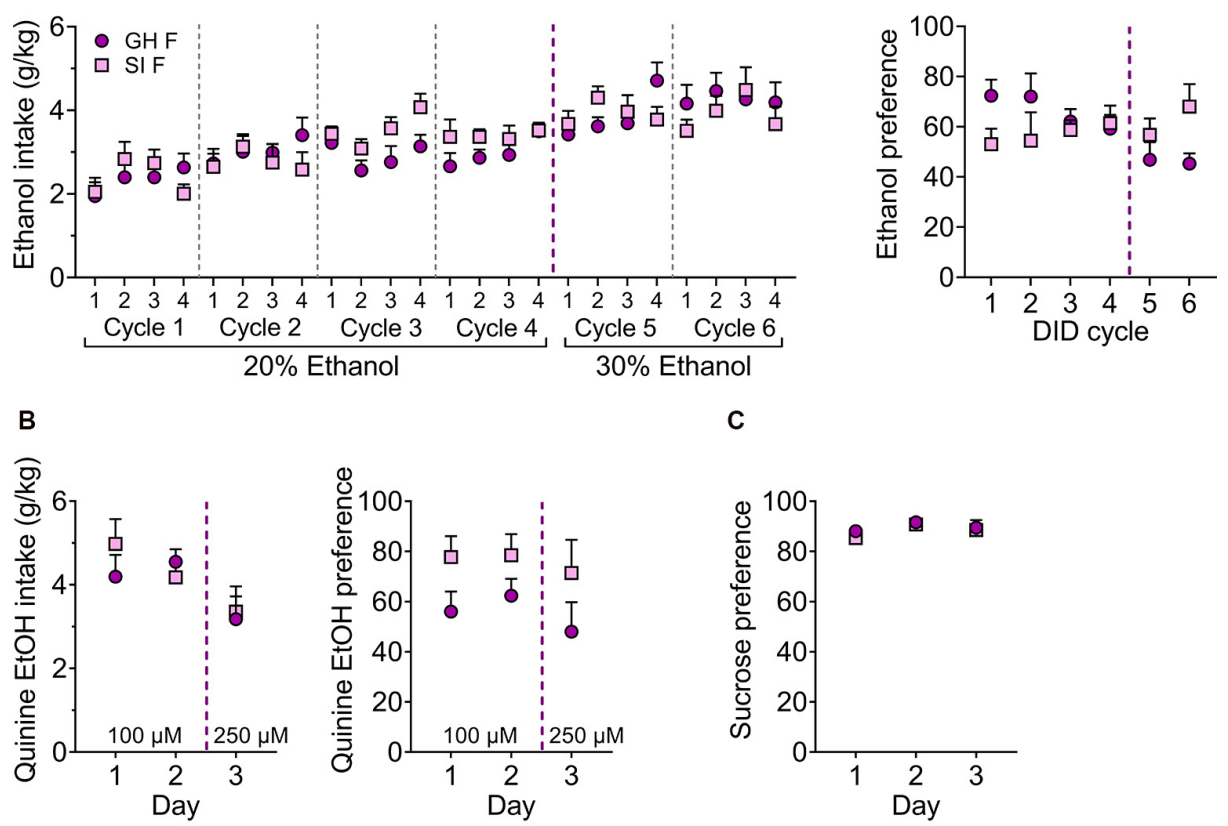

C

D

Males
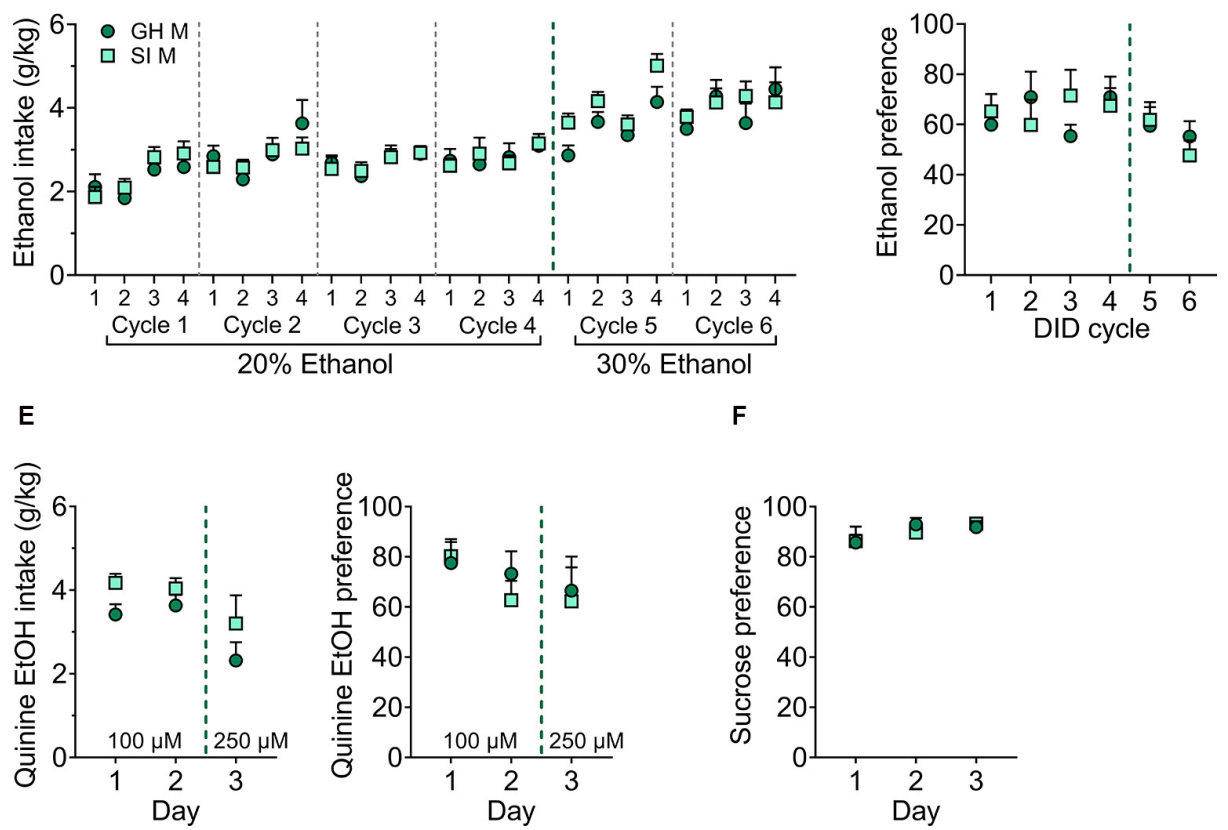

FIGURE 3 | Effects of adolescent social isolation on home-cage ethanol drinking and reward and aversion sensitivity in adult female (A-C) and male (D-F) mice. (A) There are no effects of adolescent SI on binge ethanol consumption (left) or 24-h ethanol preference (right) across 6 weeks of 20\% and $30 \%$ ethanol in a modified EtOH DID paradigm in females. (B) Adolescent GH and SI females display similar consumption of quinine-adulterated ethanol (left) and preference for it over water (right) across multiple quinine concentrations. (C) Adolescent SI does not alter preference for a 1\% sucrose solution over water in female mice. (D-F) Similarly, adolescent SI in males does not alter ethanol intake or preference (D), quinine-adulterated ethanol intake or preference (E), or $1 \%$ sucrose preference (F).

main effect of housing condition: $F_{(1,18)}=0.025, p=0.874$; time by housing condition interaction: $\left.F_{(2,36)}=0.331, p=0.720\right)$. Altogether, results from our drinking experiments suggest that binge ethanol consumption, aversion-resistant ethanol intake, and general reward sensitivity were unaltered by adolescent social isolation. 


\section{Home Cage Social Interaction}

We found a robust effect of adolescent, but not adult, social isolation on increased social behavior in adulthood using a social interaction paradigm in a novel environment. We further probed the stability and generalizability of this phenotype using a home cage social interaction test in which the experimental mouse remained in its home cage and a novel intruder conspecific was placed in the cage for 5 min (Figure 4; GH females $n=9$, SI females $n=9$, GH males $n=10$, SI males $n=9$ ). Adolescent SI males and females again showed greater social interaction in this paradigm. A two-way ANOVA on the total number of social interaction bouts (Figure 4A) showed a main effect of housing condition $\left(F_{(1,33)}=19.08, p=0.0001\right)$ and no effect of $\operatorname{sex}\left(F_{(1,33)}=3.99, p=0.054\right)$ or sex by housing interaction $\left(F_{(1,33)}=1.06, p=0.310\right)$. Post hoc $t$-tests confirmed this effect occurred in both females $\left(t_{(33)}=2.33\right.$, adjusted $\left.p=0.026\right)$ and males $\left(t_{(33)}=3.87\right.$, adjusted $\left.p=0.001\right)$. This increased interaction was true for both head-to-head and head-to-tail interactions. Head-to-head (Figure 4B): main effect of housing $\left(F_{(1,33)}=9.78\right.$, $p=0.004)$, no effect of $\operatorname{sex}\left(F_{(1,33)}=4.13, p=0.050\right)$, and no interaction $\left(F_{(1,33)}=0.002, p=0.961\right)$; post hoc $t$-tests: $p s>0,05$. Head-to-tail (Figure 4C): main effect of housing $\left(F_{(1,33)}=16.26\right.$, $p=0.0003)$, no effect of $\operatorname{sex}\left(F_{(1,33)}=1.72, p=0.198\right)$, and no interaction $\left(F_{(1,33)}=2.43, p=0.128\right)$; post hoc $t$-tests showed the effect was driven by males: females $\left(t_{(33)}=1.73\right.$, adjusted $p=0.094)$, males $\left(t_{(33)}=4.01\right.$, adjusted $\left.p=0.0007\right)$. In contrast to social interactions, there was no effect of adolescent SI on digging or climbing behaviors (Figures 4D,E). Two-way ANOVAs on the number of digging bouts and the number of climbing bouts showed no effects of housing condition, sex, or an interaction $(p s>0.05)$.

Given this distribution of behaviors during the home cage assay, adolescent SI mice spent a greater proportion of time engaged in social interaction than their GH counterparts (Figure 4F). A two-way ANOVA on the percent time spent exploring a novel social partner revealed a significant main effect of housing $\left(F_{(1,33)}=7.59, p=0.010\right)$ but no main effect of $\operatorname{sex}\left(F_{(1,33)}=0.055, p=0.815\right)$ or interaction between these variables $\left(F_{(1,33)}=2.44, p=0.127\right)$. Post hoc analysis showed that the effect of social isolation was driven by males $\left(t_{(33)}=3.09\right.$, adjusted $p=0.008$ ) but did not occur in females. However, the duration of the first interaction bout was longer in adolescent SI mice of both sexes (Figure 4G). A two-way ANOVA assessing the duration of the first bout of social interaction revealed a significant main effect of housing condition $\left(F_{(1,33)}=11.23, p=0.002\right)$, but no main effect of $\operatorname{sex}\left(F_{(1,33)}=0.109, p=0.742\right)$ or significant sex by housing condition interaction $\left(F_{(1,33)}=0.143, p=0.707\right)$. Post hoc analysis confirmed that both SI females and males spent more time interacting with a novel social partner during this first bout than their GH counterparts (females: $t_{(33)}=2.61$, adjusted $p=0.027$; males: $t_{(33)}=2.13$, adjusted $\left.p=0.040\right)$. Interestingly, however, SI mice had a longer latency to first approach the stranger mouse, suggesting some initial inhibition of this hypersocial behavior (data not shown). A two-way ANOVA revealed a main effect of housing condition $\left(F_{(1,33)}=19.00, p<0.001\right)$, but no main effect of $\operatorname{sex}\left(F_{(1,33)}=2.06, p=0.160\right)$ or sex by housing interaction $\left(F_{(1,33)}=1.35, p=0.254\right)$. Post hoc analysis revealed that SI males and females took significantly more time to approach the novel social partner than their $\mathrm{GH}$ counterparts ( $\mathrm{GH}$ females vs. SI females: $t_{(33)}=2.23$, adjusted $p=0.039$; GH males vs. SI males: $t_{(33)}=3.95$, adjusted $p=0.001)$. Despite this initial delay in interaction, the overall results support our initial findings that adolescent social isolation produces an aberrant hyper-social phenotype in adulthood in C57BL/6J mice.

\section{DISCUSSION}

These studies were designed to assess whether the harmful and translationally-relevant behavioral consequences of adolescent SI well-characterized in rats can be reliably recapitulated in C57BL/6J mice, the most common laboratory mouse background strain. We further sought to determine whether adolescence is a critical period for behavioral plasticity or whether a similar long-term social isolation in adulthood impacts these pathologyrelated behaviors. Surprisingly, we did not see any consistent phenotypes following adult SI, as mice displayed an anxiogenic phenotype in the light/dark box assay (Figure 2E) but not on any other measures of anxiety-like behavior. These findings indicate that singly housing mice in adulthood, as is done routinely in alcohol and drug self-administration studies, among others, does not alter basal behavioral states in C57BL/6J mice; thus, adult isolation is not a major confounding variable for most behavioral assays including those measured herein. Similarly, we found few effects of adolescent social isolation on performance in a battery of behaviors, which was surprising given the literature showing the deleterious effects of stress during the adolescent period on adult behaviors. However, the most robust effect of adolescent social isolation we observed was that it promoted social behavior in adulthood in both sexes (Figures 1D, 4), an effect remarkably similar in nature to the stress imposed upon the mice.

Contrary to our predictions, we did not find that adolescent social isolation increases anxiety-like behavior in male or female C57BL/6J mice (Figure 1). In fact, following adolescent isolation, adult female mice spent more time in the open arms of the elevated plus-maze on average, a behavior that is classically interpreted as a sign of anxiolysis (Figure 1B). This anxiolytic effect of adolescent isolation in mice has been reported elsewhere (Võikar et al., 2005; Lopez and Laber, 2015). Previous studies have also found some evidence that adolescent social isolation induces an anxiogenic phenotype in the light/dark box and hyperlocomotion in the open field test in mice (Võikar et al., 2005; Gan et al., 2014; Amiri et al., 2015; Medendorp et al., 2018), but these results have not always been reported (Koike et al., 2009). In contrast, we found no effect on adult social isolation on anxiety-like behavior in the EPM (Figure 2B), suggesting some adolescent period specificity for this effect. Intriguingly, we found that adult social isolation increased anxiety-like behavior in the light/dark box, suggesting that if anything, adult isolation produces the opposite effect of adolescent isolation. However, in both cohorts, other measures of anxiety-like behavior did not recapitulate 
A

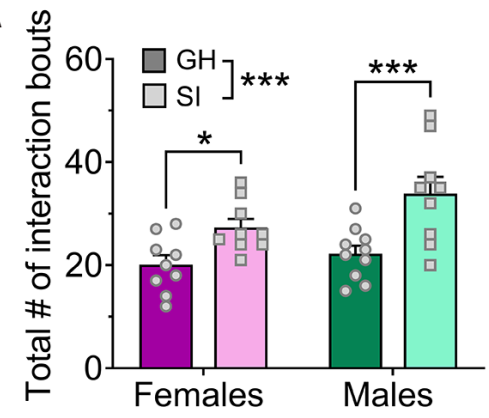

D

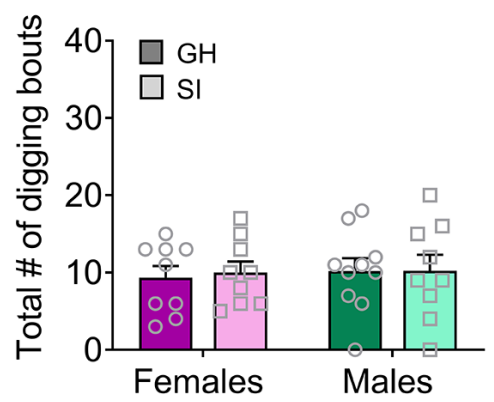

$\mathrm{F}$

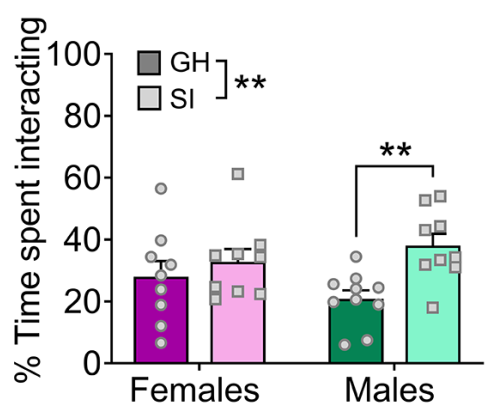

B

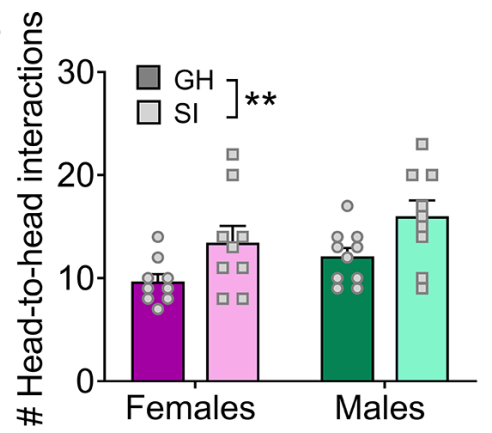

E

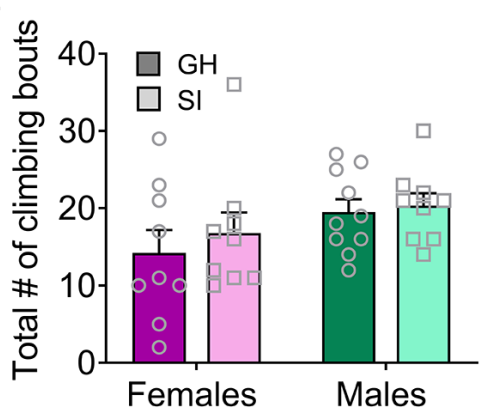

G

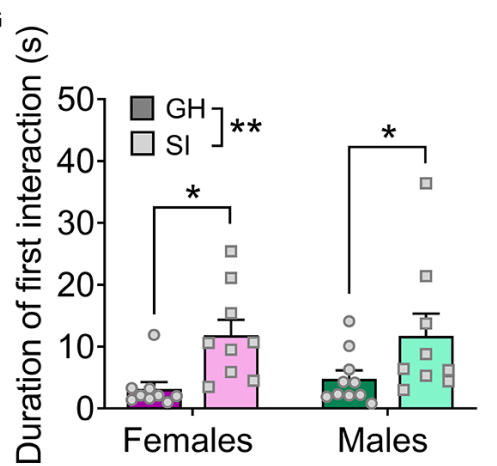

FIGURE 4 | Effects of adolescent social isolation on home cage social interaction in adulthood. (A) Adolescent SI mice display an increased number of social interaction bouts in both males and females. (B,C) This overall phenotype is present when only head-to-head interactions $\mathbf{( B )}$ or head-to-tail interactions $\mathbf{( C )}$ are considered. (D,E) In contrast, digging (D) and climbing (E) behaviors are not altered by adolescent SI. (F) Adolescent SI mice spend a greater proportion of the 5 min assay interacting with the stranger mouse than their GH counterparts, an effect driven by males. (G) The duration of the first social interaction bout is longer in adolescent SI mice of both sexes. Data are expressed as means + SEM; ${ }^{\star} p<0.05,{ }^{\star *} p<0.01,{ }^{\star \star *} p<0.001$ between groups.

these effects, suggesting there are no reliable effects of social isolation at either time point on adult anxiety-related behavior in C57BL/6J mice. We should note order effects may explain the observed differences anxiety phenotypes observed in our adult and adolescent isolation cohorts, as in each cohort we observed anxiety-relevant effects of SI on the first but not subsequent anxiety assays. However, because the phenotype observed in the first anxiety assay in adult- and adolescentisolated groups were opposite this does not suggest a broader generalized effect of isolation that can be measured upon the first assay only. Furthermore, evidence in the literature suggests that anxiety is not particularly sensitive to order effects (McIlwain et al., 2001). Studies in rats have demonstrated

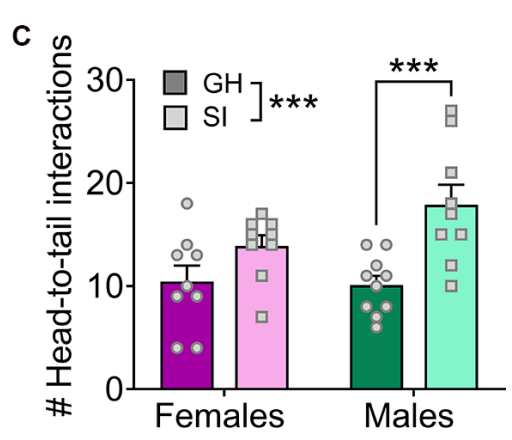

that adolescent isolation produces a stable and repeatable anxiety-like phenotype across the lifespan (Skelly et al., 2015; Butler et al., 2016). The transient nature of the observed effects of protracted social isolation on subsequent anxiety in these studies suggests that isolation does not produce a robust anxiety phenotype in C57BL/6J mice. Perhaps our most striking finding is that isolation rearing during adolescence increased social exploration and interaction in adulthood. Specifically, we found that preference for a novel social partner increased in both males and females following protracted adolescent isolation (Figure 1D). We extended this finding in a home cage social interaction test with a novel intruding conspecifics (Figure 4), demonstrating that this hypersocial behavior occurs 
in both familiar and novel environments. Aberrantly high social exploration may be maladaptive in settings in which social caution or defensive behavior is more appropriate, such as during exposure to an unfamiliar intruder. This phenotype is similar to that observed in some developmental disorders such as Williams' Syndrome, in which individuals inappropriately approach and engage with strangers. However, as this behavior occurred following a long delay before approaching the stranger mouse, the social phenotype of the adolescent SI mice could be a compensatory mechanism that promotes an adaptive social phenotype beneficial in certain contexts that require social affiliation for survival. This pro-social interpretation has previously been reported to occur in female mice following exposure to a developmental stressor (Koike et al., 2009; Bondar et al., 2018). Interestingly, many groups have reported the exact opposite effect of adolescent isolation on social behavior in mice, finding that this developmental stressor decreases social interest in adulthood (Balemans et al., 2010; Medendorp et al., 2018). Nonetheless, reduced social learning (Kercmar et al., 2011) and aberrant social behavior when placed back into group housing in adulthood (Endo et al., 2018) have also been reported following post-weaning isolation in C57BL/6J male and female mice, further supporting a specific role for peri-adolescent social isolation in abnormal adult social behavior. This is unsurprising given that this is a crucial developmental period for the development of prosocial behaviors (Spear, 2004; Panksepp and Lahvis, 2007; Panksepp et al., 2007).

Interestingly, we did not identify a robust effect of isolation in adulthood on measures of social interaction (Figure 2D), further suggesting that adolescence is a critical period for the development of sensitivity to social reward. We also tested interest in a non-social novel object following adolescent social isolation and found no significant effect of rearing condition on novel object preference (Figure 1F). Again, no differences in novel object preference emerged following social isolation in adulthood, although $\mathrm{GH}$ males spent more total time exploring the social partner and novel object combined than SI males or GH females (Figure 2F). One factor to consider when interpreting the current findings is that adolescent $\mathrm{GH}$ animals were isolated in early adulthood for home cage drinking studies, at a similar age and for a similar amount of time before subsequent behavioral testing as the adult SI cohort. However, as our analyses did not reveal any stable differences between adult GH and SI groups, it is unlikely that isolation in adulthood is a confounding factor affecting the observed behavior of adult isolated animals that were group-housed throughout adolescence. As such, we interpret these findings as indicating that adolescence is the critical period during which social isolation alters social exploration in adulthood.

Prolonged social isolation during adolescence or adulthood has also been reported to impact aspects of fear memory formation in rats and mice (Pibiri et al., 2008; Pinna et al., 2008; Lukkes et al., 2009a; Okada et al., 2015; Pinna, 2019). Here we tested the effect of sex and housing condition on fear learning across six tones/foot shock pairings. We did not identify any effect of housing condition on fear memory formation following adolescent isolation (Figure 1G) but did observe delayed acquisition following adult isolation, however, final acquisition was similar across all groups (Figure 2G). Together, these results suggest that singly housing C57BL/6J mice during adolescence or adulthood does not reliably impact fear memory formation.

Adolescent isolation has been demonstrated to increase alcohol self-administration in male rats and both male and female mice (Lopez et al., 2011; Butler et al., 2014b, 2016; Lopez and Laber, 2015; Skelly et al., 2015). Here, we evaluated adolescent social isolation on binge alcohol drinking using a modified DID paradigm and found no effects on $20 \%$, $30 \%$, and quinine-adulterated $20 \%$ ethanol consumption or preference, nor on a rewarding $1 \%$ sucrose solution, in either sex (Figure 3). Our results are inconsistent with the findings of Lopez and colleagues (Lopez and Laber, 2015), who found that adolescent social isolation in C57 mice produced a small but significant increase in alcohol consumption at a single time point. However, that study did not exam chronic home cage ethanol self-administration. Regardless, our data indicate that perhaps the effects of chronic social stress in adolescence on ethanol drinking are less robust than the effects reported in rats. Interestingly, adolescent social isolation has been reported to produce a protracted increase in ethanol intake and preference in male $\mathrm{C} 57 \mathrm{BL} / 6 \mathrm{~J}$ mice given intermittent access to ethanol in their home cage, but only at a relatively low ethanol concentration (5\%); these differences disappeared when animals were offered a higher concentration of ethanol (20\%; Advani et al., 2007). Together, these findings generally suggest that adolescent isolation does not reliably produce a translationally relevant escalation of ethanol self-administration in $\mathrm{C} 57 \mathrm{BL} / 6 \mathrm{~J}$ mice.

One important point to consider when comparing our findings to other published studies on adolescent isolation and subsequent behavioral disturbances are the timing and duration of the social isolation to which animals were exposed. As others have noted (Lukkes et al., 2009b; Walker et al., 2019) the age at which isolation stress is initiated can impact the effects of this stress on behavior. In these studies, we separated animals at PD 28, which is consistent with a well-established adolescent isolation paradigm commonly used in male rats (Butler et al., 2014a, 2016; Skelly et al., 2015). However, others have isolated animals earlier in adolescence; for example, Walker and colleagues separated $\mathrm{C} 57 \mathrm{BL} / 6 \mathrm{~J}$ males and females from PD 22-42 and did not find that isolation during this period increased EPM open arm time (Walker et al., 2020). Given the rapid shifts in hormonal and neuroendocrine profiles across adolescence and puberty in rodents, slight differences in the onset of isolation could potentially have significant long-term behavioral implications (Walker et al., 2019). These authors also re-socialized isolated animals at the end of this 3-week separation period, whereas our isolates remained singly housed throughout these studies. The duration of isolation before commencing behavioral testing also varies across studies and might explain some of the variability in findings. For example, Võikar et al. (2005) isolated male C57BL/6J mice at PD 28, but the duration of their isolation period was a bit longer 
than ours (7 weeks as opposed to 6). This group found that male isolates displayed hyperactivity in the EPM, but increased anxiety-like behavior in the light/dark box as well as impaired novel object recognition. The extra week of isolation may partly explain the differences observed by this group and the findings reported here. Similarly, other groups have used shorter isolation periods (beginning around PD28 and ending around PD60) and report findings that diverge slightly from what we report here (Lopez et al., 2011; Lopez and Laber, 2015; Huang et al., 2017). Specifically, Lopez and colleagues found that adolescent isolation did increase both anxiety-like behavior and alcohol self-administration in male and female C57Bl/6J mice; perhaps initiating drinking earlier in adulthood unmasks a phenotype not seen in our studies. In general, it seems that a standardized adolescent social isolation protocol designed with strain- and sex-specific differences in the timing of puberty and corresponding hormonal fluctuations in mind would meaningfully increase our collective ability to identify the critical periods of adolescence during which exposure to isolation stress is most deleterious.

An important component of understanding the specific periods during which adolescent animals are most sensitive to social isolation stress, future work should consider fluctuations in gonadal and stress hormone signaling during this time. Fluctuations in gonadal hormone during the postnatal period encompassing adolescence have been demonstrated to regulate social behaviors in rodents and humans, including prosocial, aggressive, and sexual behaviors (Bell, 2018). Similarly, the hormonal stress response is markedly different in adolescence as compared to early childhood or adulthood (Sapolsky and Meaney, 1986; Romeo, 2010); for example, stress-induced corticosterone release is protracted in adolescence, and this stress hormone response appears to sensitize upon repeated presentations of a stressor (Romeo et al., 2016). Crucially, there is some evidence that neuroendocrine mechanisms are involved in the release of corticosterone and other stress hormones during adolescence (Romeo et al., 2016). Although much more work is needed in this area, the divergent hormonal milieu experienced by males and females during puberty may partly explain altered stress sensitivity and any divergence in the long-term consequences of chronic social stress in males and females. We did not measure stress hormones or track the estrus cycle in these studies, but these factors may partly explain some of the sex differences observed herein. Future work assessing the interaction of these endocrine signals and their impact on the behavioral and physiological consequences of chronic adolescent stress exposure would be immensely valuable in general.

\section{REFERENCES}

Advani, T., Hensler, J. G., and Koek, W. (2007). Effect of early rearing conditions on alcohol drinking and 5-HT1A receptor function in C57BL/6J mice. Int. J. Neuropsychopharmacol. 10, 595-607. doi: 10.1017/s1461145706007401

Amiri, S., Haj-Mirzaian, A., Rahimi-Balaei, M., Razmi, A., Kordjazy, N., Shirzadian, A., et al. (2015). Co-occurrence of anxiety and depressive-like behaviors following adolescent social isolation in male mice; possible role of nitrergic system. Physiol. Behav. 145, 38-44. doi: 10.1016/j.physbeh.2015. 03.032
In general, we found that $\mathrm{C} 57 \mathrm{BL} / 6 \mathrm{~J}$ mice are not reliably sensitive to isolation stress. Beyond the findings outlined herein, others have presented some evidence that single housing may not be experienced as adversity among C57BL/6J mice (Bartolomucci et al., 2003; Arndt et al., 2009), and in fact may decrease social stress in males of this species (Singewald et al., 2009). Others have not found evidence to support a protective effect of adolescent social isolation in female C57BL/6J mice (Martin and Brown, 2010). Interestingly, the majority of studies reporting a behavioral effect of adolescent isolation on anxiety-like behavior, fear memory formation or drug self-administration in have initiated isolation at the same time that plays behavior is typically increasing, suggesting that disruption of play behavior may be a major contributor to this phenotype (Walker et al., 2019). As mice engage in less social play in adolescence than rats, this may partly explain the variability in the behavioral effects of adolescent isolation rearing reported here and elsewhere. Although, these findings present an issue for researchers interested in identifying the link between developmental stress and psychopathology using mouse models on a C57BL/6J strain, the most common background for genetic manipulation, it also suggests that experimentally-mandated individual housing in adolescence or adulthood may not produce confounding effects on basal behavioral states that experimenters prefer to avoid.

\section{DATA AVAILABILITY STATEMENT}

All datasets presented in this study are included in the article.

\section{ETHICS STATEMENT}

The animal study was reviewed and approved by Weill Cornell Medicine Institutional Animal Care and Use Committee.

\section{AUTHOR CONTRIBUTIONS}

JR-I and MS collected and analyzed the data. JR-I, MS, and KP designed the studies and wrote and edited the manuscript.

\section{FUNDING}

This research was supported by a Brain and Behavior Research Foundation NARSAD Young Investigator Award (KP), Kellen Foundation Junior Faculty Award (KP), and National Institute on Alcohol Abuse and Alcoholism grants R00AA023559 (KP), R01AA027645 (KP), and F32AA025530 (MS).

Arakawa, H. (2018). Ethological approach to social isolation effects in behavioral studies of laboratory rodents. Behav. Brain Res. 341, 98-108. doi: 10.1016/j.bbr. 2017.12.022

Arndt, S. S., Laarakker, M. C., van Lith, H. A., van der Staay, F. J., Gieling, E., Salomons, A. R., et al. (2009). Individual housing of mice-impact on behaviour and stress responses. Physiol. Behav. 97, 385-393. doi: 10.1016/j. physbeh.2009.03.008

Balemans, M. C., Huibers, M. M., Eikelenboom, N. W., Kuipers, A. J., van Summeren, R. C., Pijpers, M. M., et al. (2010). Reduced exploration, increased anxiety and altered social behavior: autistic-like features of euchromatin 
histone methyltransferase 1 heterozygous knockout mice. Behav. Brain Res. 208, 47-55. doi: 10.1016/j.bbr.2009.11.008

Bartolomucci, A., Palanza, P., Sacerdote, P., Ceresini, G., Chirieleison, A., Panerai, A. E., et al. (2003). Individual housing induces altered immuno-endocrine responses to psychological stress in male mice. Psychoneuroendocrinology 28, 540-558. doi: 10.1016/s0306-4530(02)00039-2

Becker, H. C., and Ron, D. (2014). Animal models of excessive alcohol consumption: recent advances and future challenges. Alcohol 48, 205-208. doi: $10.1016 /$ j.alcohol.2014.04.001

Bell, M. R. (2018). Comparing postnatal development of gonadal hormones and associated social behaviors in rats, mice, and humans. Endocrinology 159, 2596-2613. doi: 10.1210/en.2018-00220

Blakemore, S. J., and Robbins, T. W. (2012). Decision-making in the adolescent brain. Nat. Neurosci. 15, 1184-1191. doi: 10.1038/nn.3177

Bondar, N. P., Lepeshko, A. A., and Reshetnikov, V. V. (2018). Effects of early-life stress on social and anxiety-like behaviors in adult mice: sex-specific effects. Behav. Neurol. 2018:1538931. doi: 10.1155/2018/1538931

Bray, J. H., Adams, G. J., Getz, J. G., and Stovall, T. (2001). Interactive effects of individuation, family factors and stress on adolescent alcohol use. Am. J. Orthopsychiat. 71, 436-449. doi: 10.1037/0002-9432.71.4.436

Burke, A. R., McCormick, C. M., Pellis, S. M., and Lukkes, J. L. (2017). Impact of adolescent social experiences on behavior and neural circuits implicated in mental illnesses. Neurosci. Biobehav. Rev. 76, 280-300. doi: 10.1016/j. neubiorev.2017.01.018

Butler, T. R., Ariwodola, O. J., and Weiner, J. L. (2014a). The impact of social isolation on HPA axis function, anxiety-like behaviors, and ethanol drinking. Front. Integr. Neurosci. 7:102. doi: 10.3389/fnint.2013.00102

Butler, T. R., Carter, E., and Weiner, J. L. (2014b). Adolescent social isolation does not lead to persistent increases in anxiety- like behavior or ethanol intake in female long-evans rats. Alcohol. Clin. Exp. Res. 38, 2199-2207. doi: $10.1111 /$ acer. 12476

Butler, T. R., Karkhanis, A. N., Jones, S. R., and Weiner, J. L. (2016). Adolescent social isolation as a model of heightened vulnerability to comorbid alcoholism and anxiety disorders. Alcohol. Clin. Exp. Res. 40, 1202-1214. doi: 10.1111/acer. 13075

Caruso, M. J., Seemiller, L. R., Fetherston, T. B., Miller, C. N., Reiss, D. E., Cavigelli, S. A., et al. (2018). Adolescent social stress increases anxiety-like behavior and ethanol consumption in adult male and female C57BL/6J mice. Sci. Rep. 8:10040. doi: 10.1038/s41598-018-28381-2

Casey, B. J., and Jones, R. M. (2010). Neurobiology of the adolescent brain and behavior: implications for substance use disorders. J. Am. Acad. Child Adolesc. Psychiatry 49, 1189-1201; quiz 1285. doi: 10.1016/j.jaac.2010. 08.017

Casey, B. J., Jones, R. M., Levita, L., Libby, V., Pattwell, S. S., Ruberry, E. J., et al. (2010). The storm and stress of adolescence: insights from human imaging and mouse genetics. Dev. Psychobiol. 52, 225-235. doi: 10.1002/dev.20447

Crowley, N. A., Bloodgood, D. W., Hardaway, J. A., Kendra, A. M., McCall, J. G., Al-Hasani, R., et al. (2016). Dynorphin controls the gain of an amygdalar anxiety circuit. Cell Rep. 14, 2774-2783. doi: 10.1016/j.celrep.2016.02.069

Deutsch, A. R., Chernyavskiy, P., Steinley, D., and Slutske, W. S. (2015). Measuring peer socialization for adolescent substance use: a comparison of perceived and actual friends' substance use effects. J. Stud. Alcohol Drugs 76, 267-277. doi: 10.15288/jsad.2015.76.267

Eichelsheim, V. I., Buist, K. L., Dekovic, M., Wissink, I. B., Frijns, T., van Lier, P. A., et al. (2010). Associations among the parent-adolescent relationship, aggression and delinquency in different ethnic groups: a replication across two Dutch samples. Soc. Psychiatry Psychiatr. Epidemiol. 45, 293-300. doi: 10.1007/s00127-009-0071-z

Eiland, L., and Romeo, R. D. (2013). Stress and the developing adolescent brain. Neuroscience 249, 162-171. doi: 10.1016/j.neuroscience.2012.10.048

Endo, N., Ujita, W., Fujiwara, M., Miyauchi, H., Mishima, H., Makino, Y., et al. (2018). Multiple animal positioning system shows that socially-reared mice influence the social proximity of isolation-reared cagemates. Commun. Biol. 1:225. doi: 10.1038/s42003-018-0213-5

Ernst, M., and Fudge, J. L. (2009). A developmental neurobiological model of motivated behavior: anatomy, connectivity, and ontogeny of the triadic nodes. Neurosci. Biobehav. Rev. 33, 367-382. doi: 10.1016/j.neubiorev.2008. 10.009
Ferdman, N., Murmu, R. P., Bock, J., Braun, K., and Leshem, M. (2007). Weaning age, social isolation and gender, interact to determine adult explorative and social behavior and dendritic and spine morphology in prefrontal cortex of rats. Behav. Brain Res. 180, 174-182. doi: 10.1016/j.bbr.2007. 03.011

Gan, J. O., Bowline, E., Lourenco, F. S., and Pickel, V. M. (2014). Adolescent social isolation enhances the plasmalemmal density of NMDA NR1 subunits in dendritic spines of principal neurons in the basolateral amygdala of adult mice. Neuroscience 258, 174-183. doi: 10.1016/j.neuroscience.2013.11.003

Hawk, S. T., Keijsers, L., Hale, W. W. 3rd., and Meeus, W. (2009). Mind your own business! Longitudinal relations between perceived privacy invasion and adolescent-parent conflict. J. Family Psychol. 23, 511-520. doi: $10.1037 / \mathrm{a} 0015426$

Huang, Q., Zhou, Y., and Liu, L. Y. (2017). Effect of post-weaning isolation on anxiety- and depressive-like behaviors of C57BL/6J mice. Exp. Brain Res. 235, 2893-2899. doi: 10.1007/s00221-017-5021-5

Hwa, L. S., Chu, A., Levinson, S. A., Kayyali, T. M., DeBold, J. F., and Miczek, K. A. (2011). Persistent escalation of alcohol drinking in C57BL/6J mice with intermittent access to $20 \%$ ethanol. Alcohol. Clin. Exp. Res. 35, 1938-1947. doi: 10.1111/j.1530-0277.2011.01545.x.

Jager, J., Yuen, C. X., Putnick, D. L., Hendricks, C., and Bornstein, M. H. (2015). Adolescent-peer relationships, separation and detachment from parents, and internalizing and externalizing behaviors: linkages and interactions. J. Early Adolesc. 35, 511-537. doi: 10.1177/0272431614537116

Karkhanis, A. N., Alexander, N. J., McCool, B. A., Weiner, J. L., and Jones, S. R. (2015). Chronic social isolation during adolescence augments catecholamine response to acute ethanol in the basolateral amygdala. Synapse 69, 385-395. doi: 10.1002/syn.21826

Karkhanis, A. N., Leach, A. C., Yorgason, J. T., Uneri, A., Barth, S., Niere, F., et al. (2019). Chronic social isolation stress during peri-adolescence alters presynaptic dopamine terminal dynamics via augmentation in accumbal dopamine availability. ACS Chem. Neurosci. 10, 2033-2044. doi: 10.1002/syn. 21826

Keijsers, L., Frijns, T., Branje, S. J., and Meeus, W. (2009). Developmental links of adolescent disclosure, parental solicitation and control with delinquency: moderation by parental support. Dev. Psychol. 45, 1314-1327. doi: $10.1037 / \mathrm{a} 0016693$

Kercmar, J., Budefeld, T., Grgurevic, N., Tobet, S. A., and Majdic, G. (2011). Adolescent social isolation changes social recognition in adult mice. Behav. Brain Res. 216, 647-651. doi: 10.1016/j.bbr.2010.09.007

Kessler, R. C., Amminger, G. P., Aguilar-Gaxiola, S., Alonso, J., Lee, S., and Ustun, T. B. (2007). Age of onset of mental disorders: a review of recent literature. Curr. Opin. Psychiatry 20, 359-364. doi: 10.1097/YCO. 0b013e32816ebc8c

Kessler, R. C., Berglund, P., Demler, O., Jin, R., Merikangas, K. R., and Walters, E. E. (2005). Lifetime prevalence and age-of-onset distributions of DSM-IV disorders in the national comorbidity survey replication. Arch. Gen. Psychiatry 62, 593-602. doi: 10.1001/archpsyc.62.6.593

Kochenderfer-Ladd, B., and Wardrop, J. L. (2001). Chronicity and instability of children's peer victimization experiences as predictors of loneliness and social satisfaction trajectories. Child Dev. 72, 134-151. doi: 10.1111/1467-8624.00270

Koike, H., Ibi, D., Mizoguchi, H., Nagai, T., Nitta, A., Takuma, K., et al. (2009). Behavioral abnormality and pharmacologic response in social isolation-reared mice. Behav. Brain Res. 202, 114-121. doi: 10.1016/j.bbr.2009.03.028

Leshem, R. (2016). Brain development, impulsivity, risky decision making, and cognitive control: integrating cognitive and socioemotional processes during adolescence-an introduction to the special issue. Dev. Neuropsychol. 41, 1-5. doi: $10.1080 / 87565641.2016 .1187033$

Lopez, M. F., Doremus-Fitzwater, T. L., and Becker, H. C. (2011). Chronic social isolation and chronic variable stress during early development induce later elevated ethanol intake in adult C57BL/6J mice. Alcohol 45, 355-364. doi: 10.1016/j.alcohol.2010.08.017

Lopez, M. F., and Laber, K. (2015). Impact of social isolation and enriched environment during adolescence on voluntary ethanol intake and anxiety in C57BL/6J mice. Physiol. Behav. 148, 151-156. doi: 10.1016/j.physbeh.2014. 11.012

Lueptow, L. M. (2017). Novel object recognition test for the investigation of learning and memory in mice. J. Vis. Exp. 30:55718. doi: 10.3791/55718 
Lukkes, J. L., Mokin, M. V., Scholl, J. L., and Forster, G. L. (2009a). Adult rats exposed to early-life social isolation exhibit increased anxiety and conditioned fear behavior and altered hormonal stress responses. Horm. Behav. 55, 248-256. doi: 10.1016/j.yhbeh.2008.10.014

Lukkes, J. L., Watt, M. J., Lowry, C. A., and Forster, G. L. (2009b). Consequences of post-weaning social isolation on anxiety behavior and related neural circuits in rodents. Front. Behav. Neurosci. 3:18. doi: 10.3389/neuro.08. 018.2009

Lyons, A. M., Lowery, E. G., Sparta, D. R., and Thiele, T. E. (2008). Effects of food availability and administration of orexigenic and anorectic agents on elevated ethanol drinking associated with drinking in the dark procedures. Alcohol. Clin. Exp. Res. 32, 1962-1968. doi: 10.1111/j.1530-0277.2008. 00784.x

Marcinkiewcz, C. A., Mazzone, C. M., D’Agostino, G., Halladay, L. R., Hardaway, J. A., DiBerto, J. F., et al. (2016). Serotonin engages an anxiety and fear-promoting circuit in the extended amygdala. Nature 537, 97-101. doi: 10.3410/f.726666423.793524613

Martin, A. L., and Brown, R. E. (2010). The lonely mouse: verification of a separation-induced model of depression in female mice. Behav. Brain Res. 207, 196-207. doi: 10.1016/j.bbr.2009.10.006

Masten, C. L., Telzer, E. H., Fuligni, A. J., Lieberman, M. D., and Eisenberger, N. I. (2012). Time spent with friends in adolescence relates to less neural sensitivity to later peer rejection. Soc. Cogn. Affect. Neurosci. 7, 106-114. doi: $10.1093 /$ scan/nsq098

McCool, B. A., and Chappell, A. M. (2009). Early social isolation in male Long-Evans rats alters both appetitive and consummatory behaviors expressed during operant ethanol self-administration. Alcohol. Clin. Exp. Res. 33, 273-282. doi: 10.1111/j.1530-0277.2008.00830.x

McIlwain, K. L., Merriweather, M. Y., Yuva-Paylor, L. A., and Paylor, R. (2001). The use of behavioral test batteries: Effects of training history. Physiol. Behav. 73, 705-717. doi: 10.1016/s0031-9384(01)00528-5

Medendorp, W. E., Petersen, E. D., Pal, A., Wagner, L. M., Myers, A. R., Hochgeschwender, U., et al. (2018). Altered behavior in mice socially isolated during adolescence corresponds with immature dendritic spine morphology and impaired plasticity in the prefrontal cortex. Front. Behav. Neurosci. 12:87. doi: 10.3389/fnbeh.2018.00087

Melendez, R. I., Middaugh, L. D., and Kalivas, P. W. (2006). Development of an alcohol deprivation and escalation effect in C57BL/6J mice. Alcohol. Clin. Exp. Res. 30, 2017-2025. doi: 10.1111/j.1530-0277.2006.00248.x

Mulligan, M. K., Rhodes, J. S., Crabbe, J. C., Mayfield, R. D., Harris, R. A., and Ponomarev, I. (2011). Molecular profiles of drinking alcohol to intoxication in C57BL/6J mice. Alcohol. Clin. Exp. Res. 35, 659-670. doi: 10.1111/j.1530-0277. 2010.01384.x

Mumtaz, F., Khan, M. I., Zubair, M., and Dehpour, A. R. (2018). Neurobiology and consequences of social isolation stress in animal model-A comprehensive review. Biomed. Pharmacother 105, 1205-1222. doi: 10.1016/j.biopha.2018. 05.086

Noom, M. J., Dekovic, M., and Meeus, W. H. (1999). Autonomy, attachment and psychosocial adjustment during adolescence: a double-edged sword? J. Adolesc. 22, 771-783. doi: 10.1006/jado.1999.0269

Okada, R., Fujiwara, H., Mizuki, D., Araki, R., Yabe, T., and Matsumoto, K. (2015). Involvement of dopaminergic and cholinergic systems in social isolation-induced deficits in social affiliation and conditional fear memory in mice. Neuroscience 299, 134-145. doi: 10.1016/j.neuroscience.2015. 04.064

Panksepp, J. B., Jochman, K. A., Kim, J. U., Koy, J. J., Wilson, E. D., Chen, Q., et al. (2007). Affiliative behavior, ultrasonic communication and social reward are influenced by genetic variation in adolescent mice. PLoS One 2:e351. doi: 10.1371/journal.pone.0000351

Panksepp, J. B., and Lahvis, G. P. (2007). Social reward among juvenile mice. Genes Brain Behav. 6, 661-671. doi: 10.1111/j.1601-183x.2006.00295.x

Paus, T. (2007). Mapping brain maturation and cognitive development during adolescence. Eur. Neuropsychopharm. 17, S217-S217. doi: 10.1016/s0924$977 \mathrm{x}(07) 70282-1$

Pibiri, F., Nelson, M., Guidotti, A., Costa, E., and Pinna, G. (2008). Decreased corticolimbic allopregnanolone expression during social isolation enhances contextual fear: a model relevant for posttraumatic stress disorder. Proc. Natl. Acad. Sci. U S A 105, 5567-5572. doi: 10.1073/pnas.0801853105
Pinna, G. (2019). Animal models of PTSD: the socially isolated mouse and the biomarker role of allopregnanolone. Front. Behav. Neurosci. 13:114. doi: 10.3389/fnbeh.2019.00114

Pinna, G., Agis-Balboa, R. C., Pibiri, F., Nelson, M., Guidotti, A., and Costa, E. (2008). Neurosteroid biosynthesis regulates sexually dimorphic fear and aggressive behavior in mice. Neurochem. Res. 33, 1990-2007. doi: 10.1007/s11064-008-9718-5

Platt, B., Cohen Kadosh, K., and Lau, J. Y. (2013). The role of peer rejection in adolescent depression. Depress. Anxiety 30, 809-821. doi: 10.1002/da.22120

Pleil, K. E., Rinker, J. A., Lowery-Gionta, E. G., Mazzone, C. M., McCall, N. M., Kendra, A. M., et al. (2015). NPY signaling inhibits extended amygdala CRF neurons to suppress binge alcohol drinking. Nat. Neurosci. 18, 545-552. doi: 10.1038/nn.3972

Rhodes, J. S., Best, K., Belknap, J. K., Finn, D. A., and Crabbe, J. C. (2005). Evaluation of a simple model of ethanol drinking to intoxication in C57BL/6J mice. Physiol. Behav. 84, 53-63. doi: 10.1016/j.physbeh.2004.10.007

Romeo, R. D. (2010). Pubertal maturation and programming of hypothalamicpituitary-adrenal reactivity. Front. Neuroendocrinol. 31, 232-240. doi: 10.1016/j.yfrne.2010.02.004

Romeo, R. D., Bellani, R., Karatsoreos, I. N., Chhua, N., Vernov, M., Conrad, C. D., et al. (2006). Stress history and pubertal development interact to shape hypothalamic-pituitary-adrenal axis plasticity. Endocrinology 147, 1664-1674. doi: 10.1210/en.2005-1432

Romeo, R. D., Patel, R., Pham, L., and So, V. M. (2016). Adolescence and the ontogeny of the hormonal stress response in male and female rats and mice. Neurosci. Biobehav. Rev. 70, 206-216. doi: 10.1016/j.neubiorev.2016.05.020

Romer, D. (2010). Adolescent risk taking, impulsivity, and brain development: implications for prevention. Dev. Psychobiol. 52, 263-276. doi: 10.1002/dev. 20442

Sapolsky, R. M., and Meaney, M. J. (1986). Maturation of the adrenocortical stress response: neuroendocrine control mechanisms and the stress hyporesponsive period. Brain Res. 396, 64-76. doi: 10.1016/s0006-8993(86)80190-1

Singewald, G. M., Nguyen, N. K., Neumann, I. D., Singewald, N., and Reber, S. O. (2009). Effect of chronic psychosocial stress-induced by subordinate colony (CSC) housing on brain neuronal activity patterns in mice. Stress 12, 58-69. doi: $10.1080 / 10253890802042082$

Skelly, M. J., Chappell, A. E., Carter, E., and Weiner, J. L. (2015). Adolescent social isolation increases anxiety-like behavior and ethanol intake and impairs fear extinction in adulthood: possible role of disrupted noradrenergic signaling. Neuropharmacology 97, 149-159. doi: 10.1016/j.neuropharm.2015. 05.025

Spear, L. P. (2004). Adolescent brain development and animal models. Ann. N Y Acad. Sci. 1021, 23-26. doi: 10.1196/annals.1308.002

Steinberg, L. (2004). Risk taking in adolescence: what changes and why? Ann. N. Y. Acad. Sci. 1021, 51-58. doi: 10.1196/annals. 1308.005

Steinberg, L. (2010). A dual systems model of adolescent risk-taking. Dev. Psychobiol. 52, 216-224. doi: 10.1002/dev.20445

Tian, S. W., Yu, X. D., Cen, L., and Xiao, Z. Y. (2019). Glutamate transporter GLT1 inhibitor dihydrokainic acid impairs novel object recognition memory performance in mice. Physiol. Behav. 199, 28-32. doi: 10.1016/j.physbeh.2018. 10.019

Trentacosta, C. J., and Shaw, D. S. (2009). Emotional self-regulation, peer rejection, and antisocial behavior: developmental associations from early childhood to early adolescence. J. Appl. Dev. Psychol. 30, 356-365. doi: 10.1016/j.appdev. 2008.12.016

Turner, R. J., and Lloyd, D. A. (2004). Stress burden and the lifetime incidence of psychiatric disorder in young adults: racial and ethnic contrasts. Arch. Gen. Psychiatry 61, 481-488. doi: 10.1001/archpsyc.61.5.481

Võikar, V., Polus, A., Vasar, E., and Rauvala, H. (2005). Long-term individual housing in C57BL/6J and DBA/2 mice: assessment of behavioral consequences. Genes Brain Behav. 4, 240-252. doi: 10.1111/j.1601-183x.2004.00106.x

Walker, D. M., Cunningham, A. M., Gregory, J. K., and Nestler, E. J. (2019). Longterm behavioral effects of post-weaning social isolation in males and females. Front. Behav. Neurosci. 13:66. doi: 10.3389/fnbeh.2019.00066

Walker, D. M., Zhou, X., Ramakrishnan, A., Cates, H. M., Cunningham, A. M., Peña, C. D., et al. (2020). Adolescent Social Isolation Reprograms the Medial Amygdala: Transcriptome and Sex Differences in Reward. bioRxiv [Preprint]. doi: $10.1101 / 2020.02 .18 .955187$ 
Whitaker, L. R., Degoulet, M., and Morikawa, H. (2013). Social deprivation enhances VTA synaptic plasticity and drug-induced contextual learning. Neuron 77, 335-345. doi: 10.1016/j.neuron.2012. 11.022

Yoneyama, N., Crabbe, J. C., Ford, M. M., Murillo, A., and Finn, D. A. (2008). Voluntary ethanol consumption in 22 inbred mouse strains. Alcohol 42, 149-160. doi: 10.1016/j.alcohol.2007.12.006

Yorgason, J. T., Calipari, E. S., Ferris, M. J., Karkhanis, A. N., Fordahl, S. C., Weiner, J. L., et al. (2016). Social isolation rearing increases dopamine uptake and psychostimulant potency in the striatum. Neuropharmacology 101, 471-479. doi: 10.1016/j.neuropharm.2015.10.025
Conflict of Interest: The authors declare that the research was conducted in the absence of any commercial or financial relationships that could be construed as a potential conflict of interest.

Copyright (c) 2020 Rivera-Irizarry, Skelly and Pleil. This is an open-access article distributed under the terms of the Creative Commons Attribution License (CC BY). The use, distribution or reproduction in other forums is permitted, provided the original author(s) and the copyright owner(s) are credited and that the original publication in this journal is cited, in accordance with accepted academic practice. No use, distribution or reproduction is permitted which does not comply with these terms. 